\title{
Anatomía radiológica del tórax
}

\author{
EDUARDO SABBAGH P.*, GERARDO MORDOJOVICH R.* y FELIPE UNDURRAGA M.*
}

\section{Radiological anatomy of the thorax}

This article is composed of two parts: I. A radiologic description of the thoracic anatomy and some concepts about lung structure, and II. A computed tomographic atlas of the thorax.

El estudio radiológico de la patología torácica, requiere como primer requisito conocer la anatomía torácica por imágenes y la estructura pulmonar básica y así entender las modificaciones que producen las distintas patologías en la imagen de las estructuras anatómicas.

A continuación presentamos una descripción radiológica simple de las estructuras anatómicas y un atlas tomográfico del tórax, que esperamos sean de utilidad al enfrentarse a un examen radiológico, como consulta comparativa.

tes:

Este artículo consta, por lo tanto, de dos par-

I. Descripción radiológica de la Anatomía Torácica y algunos conceptos de estructura pulmonar.

II. Atlas tomográfico del tórax. Descripción radiológica de la Anatomía Torácica.

\section{Contornos vasculares del mediastino}

Analizando la radiografía simple (Figura 1a y 1b) el contorno vascular derecho del mediastino corresponde siguiéndolo desde arriba hacia abajo, a la interfase producida por la vena braquiocefálica derecha (formada por la conjunción de la yugular y subclavia), que al unirse con la vena braquiocefálica izquierda (invisible en la radiografía de tórax por su trayectoria intramediastínica) forman la vena cava superior, para finalmente continuarse con el contorno derecho del corazón, que corresponde a la aurícula derecha. En algunos casos es posible ver en la parte baja una interfase recta que llega hasta el diafragma correspondiente a la vena cava inferior.

El contorno izquierdo del mediastino comienza por la interfase cóncava dada por la arteria subclavia izquierda (que nace del cayado aórtico), luego se continúa con el botón aórtico que corresponde a la porción más posterior del cayado aórtico. A continuación se aprecia el espacio subaórtico o ventana aortopulmonar, el hilio izquierdo y finalmente el contorno izquierdo del corazón. Este contorno cardíaco en su parte más alta corresponde a la orejuela auricular izquierda (la aurícula izquierda se encuentra en la parte posterior) que abraza el corazón hacia adelante. A continuación el tracto de salida del ventrículo derecho y finalmente el ventrículo izquierdo (este también es posterior y sólo un borde de él se asoma en el contorno cardíaco izquierdo).

\section{Árbol traqueobronquial}

La tráquea se observa como una columna radiolúcida que se extiende desde la glotis hasta la carina (Figura 2). De longitud variable, pero diámetro ántero-posterior, aproximado de 19,5 mm y transverso, aproximado de $17,5 \mathrm{~mm}$ (se acepta hasta $25 \mathrm{~mm}$ como normal). A nivel de la carina la tráquea se divide en dos bronquios principales, de calibre similar, el derecho y el izquierdo.

\section{Sistema bronquial derecho (Figuras 3, 4a y 5)}

El bronquio principal derecho es un bronquio corto que mide aproximadamente $2 \mathrm{~cm}$, presenta un ángulo abierto con respecto a la tráquea y da origen en ángulo recto al lobar superior, pasando a llamarse intermedio, el cual mide aproximadamente $4 \mathrm{~cm}$, ramificándose en lobar medio e inferior.

El bronquio lobar superior también es corto, midiendo alrededor de $1,5 \mathrm{~cm}$ y se trifurca en 3 bronquios segmentarios, el apical hacia arriba, anterior hacia adelante y posterior hacia atrás.

El bronquio lobar medio se dirige hacia adelante y hacia afuera bifurcándose horizontalmente en dos bronquios segmentarios, el lateral y el medial.

\footnotetext{
* Instituto Nacional del Tórax.
} 


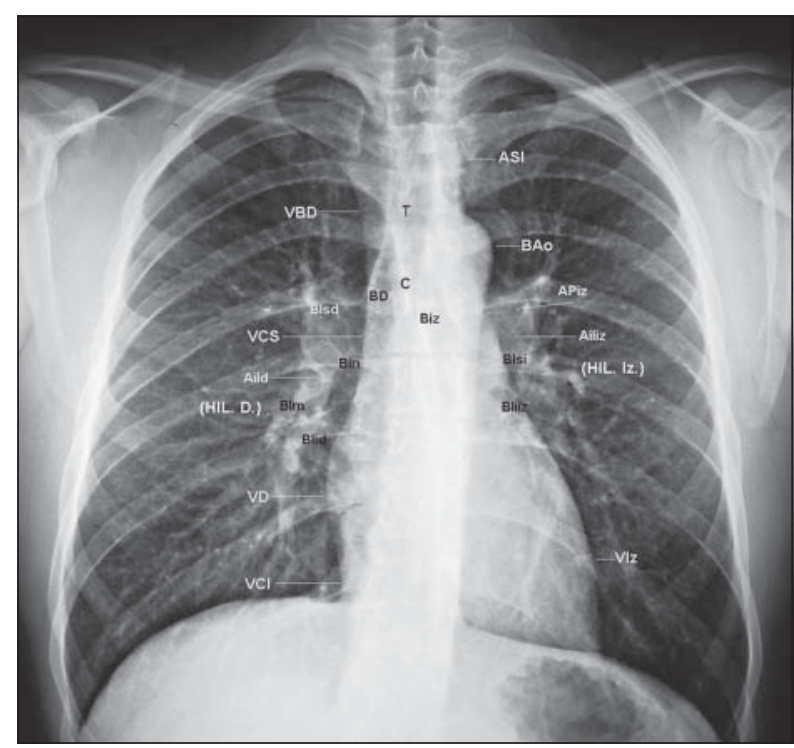

Figura 1a. Radiografía simple de tórax en proyección póstero anterior.

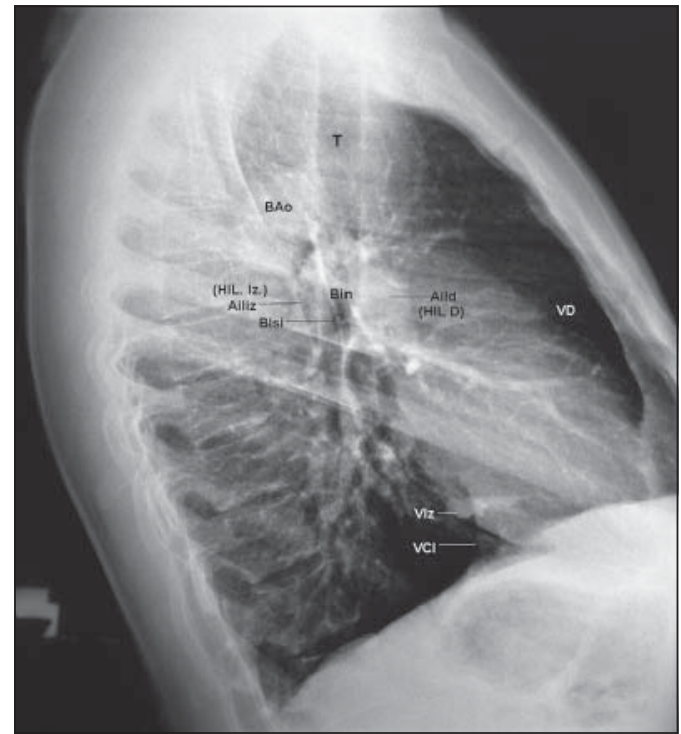

Figura 1b. Radiografía lateral.

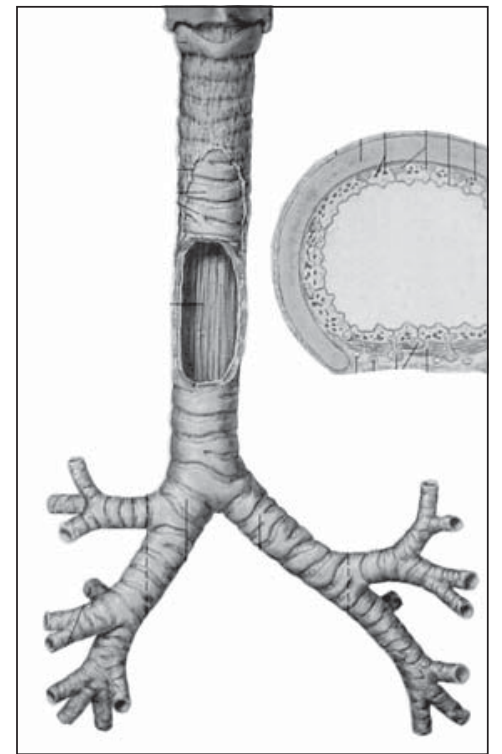

\begin{tabular}{|l|l|l|l|}
\hline \multicolumn{4}{|c|}{ Figuras 1a, 1b, 2 y 3} \\
\hline \hline VBD & Vena braquiocefálica derecha & BD & Bronquio principal derecho \\
\hline Blsd & Bronquio lobar superior derecho & Biz & Bronquio principal izquierdo \\
\hline VCS & Vena cava superior & ASI & Arteria subclavia izquierda \\
\hline Aild & Arteria interlobar derecha & BAo & Botón aórtico \\
\hline Bin & Bronquio intermedio & APiz & Arteria pulmonar izquierda \\
\hline Blm & Bronquio lobar medio & Ailiz & Arteria interlobar izquierda \\
\hline Blid & Bronquio lobar inferior derecho & Blsi & Bronquio lobar superior izquierdo \\
\hline VD & Ventrículo derecho & Bliiz & Bronquio lobar inferior izquierdo \\
\hline VCI & Vena cava inferior & VIZ & Ventrículo izquierdo \\
\hline T & Tráquea & (HIL D) & Hilio derecho \\
\hline C & Carina & (HIL Iz) & Hilio Izquierdo \\
\hline
\end{tabular}

Figura 2. Tráquea.

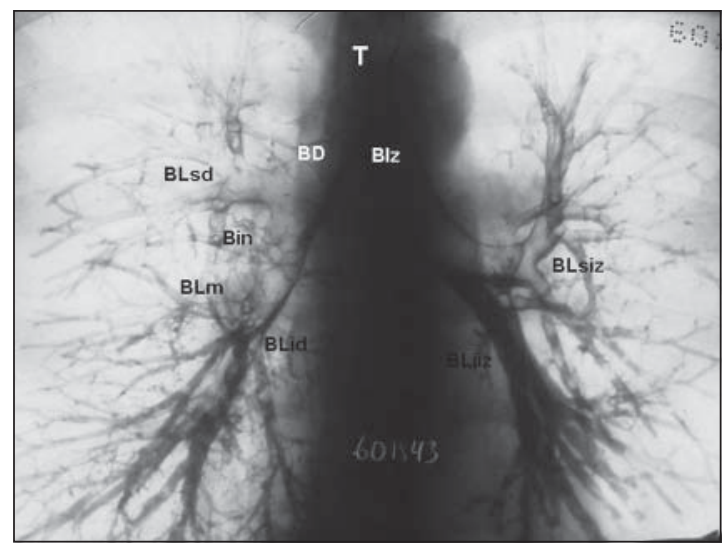

Figura 3. Árbol tráqueo bronquial.
El bronquio lobar inferior da origen a 5 bronquios segmentarios, el apical que nace hacia atrás prácticamente en su origen, casi a la misma altura del lobar medio, y los basales que van naciendo en forma de espiral; primero el basal medial, más abajo y hacia adelante el basal anterior, luego hacia atrás y afuera el basal lateral y finalmente el basal posterior. Hay que hacer notar que los bronquios principal, intermedio, lobar inferior y basal posterior del lóbulo inferior, prácticamente forman un eje recto, con un ángulo abierto con respecto a la tráquea. 


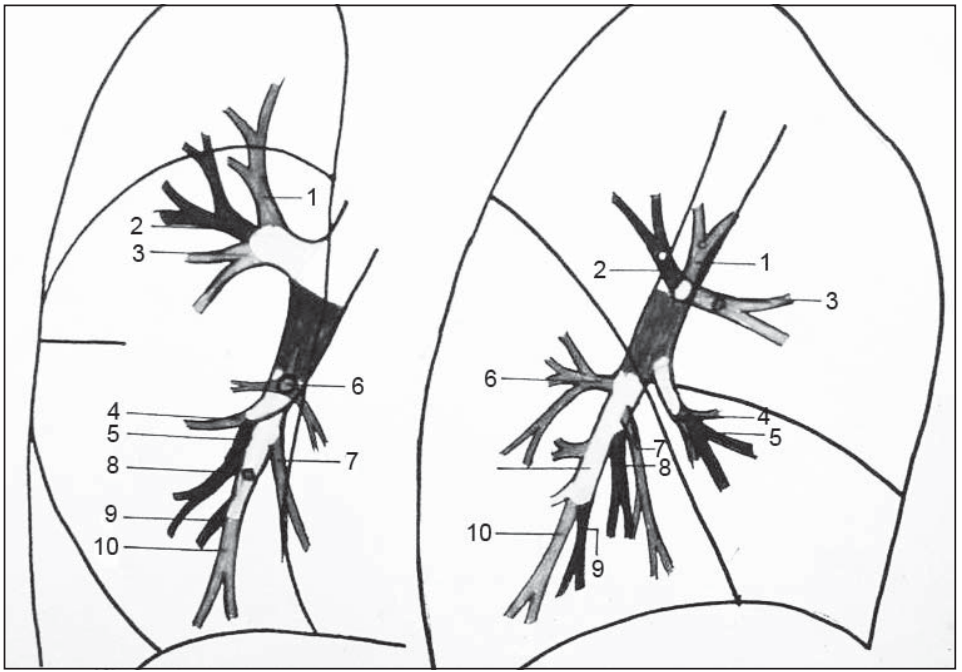

Figura 4a. Sistema bronquial derecho.

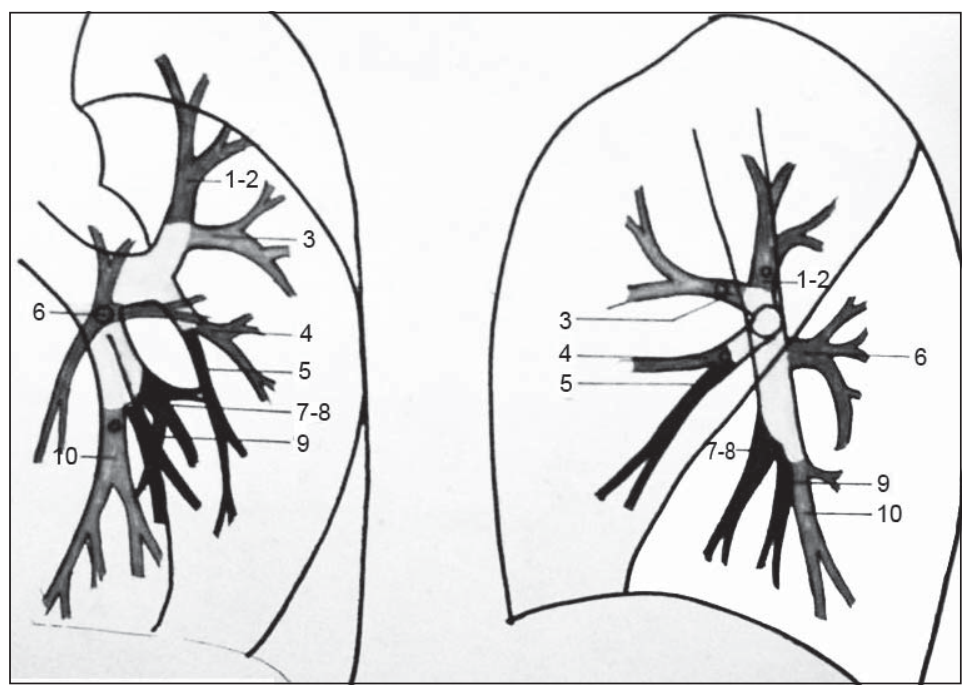

Figura 4b. Sistema bronquial izquierdo.

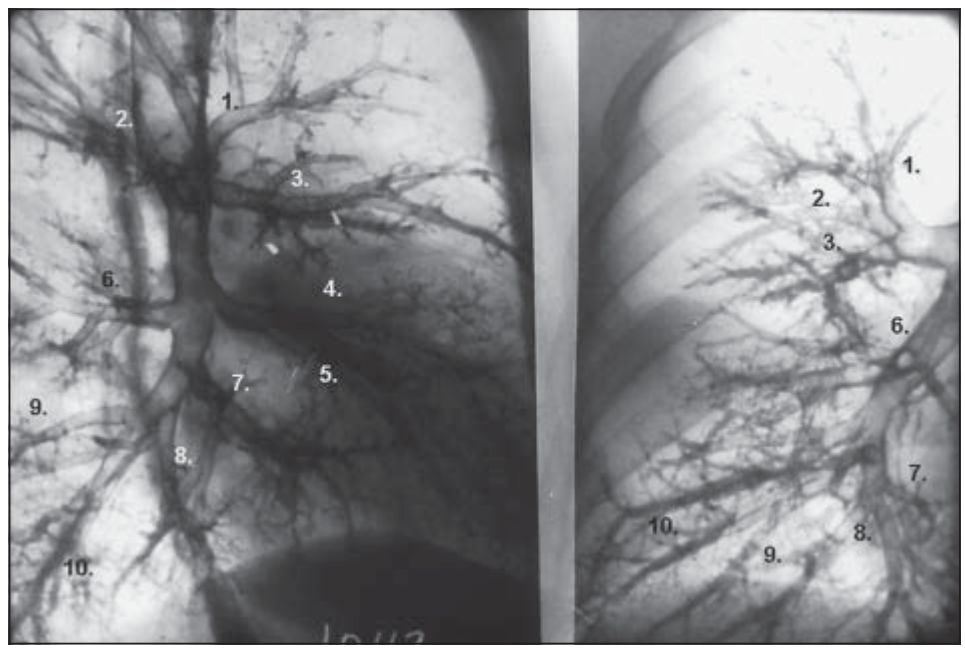

Figura 5. Árbol bronquial derecho en lateral y en frontal.

\section{Sistema bronquial izquierdo} (Figuras 3, $4 b$ y 6 )

En el lado izquierdo la anatomía bronquial es algo diferente, primero el bronquio principal es más largo, mide aproximadamente $5 \mathrm{~cm}$, de trayectoria curva y con un ángulo más pronunciado con respecto a la tráquea. Además se bifurca en dos troncos bronquiales lobares, de similar calibre, el superior y el inferior.

El bronquio lobar superior también es diferente al del lado derecho, se divide en 2 troncos: ascendente (equivalente al lobar superior derecho) que da origen

\begin{tabular}{|r|l|}
\hline \multicolumn{2}{|c|}{ Figuras $\mathbf{4 a}, \mathbf{4 b}, \mathbf{5} \mathbf{y} \mathbf{6}$} \\
\hline 1. & Segmento apical \\
\hline 2. & Segmento posterior \\
\hline 3. & Segmento anterior \\
\hline 4. & Segmento medial \\
\hline 5. & Segmento lateral \\
\hline 6. & Segmento apical \\
\hline 7. & Segmento basal medial \\
\hline 8. & Segmento basal anterior \\
\hline 9. & Segmento basal lateral \\
\hline 10. & Segmento basal posterior \\
\hline
\end{tabular}

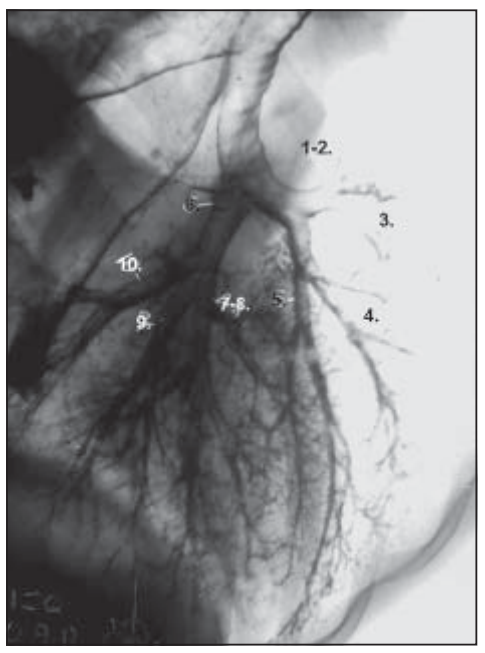

Figura 6. Árbol bronquial izquierdo oblicuo. 
al segmentario anterior y al segmentario común ápico-posterior, y al tronco descendente o lingular (equivalente al lóbulo medio), el que se divide en dos segmentos en sentido vertical, el lingular superior y lingular inferior.

El bronquio lobar inferior, al igual que en el lado derecho, da origen prácticamente en su nacimiento, al segmentario apical hacia atrás y luego a los basales. Los basales, a diferencia del lado derecho, son solamente tres y se originan simultáneamente, el basal común ántero-medial, basal lateral y basal posterior.

\section{Sistema arterial pulmonar \\ (Figuras 7, 8a y 8b)}

El sistema arterial pulmonar se origina del ventrículo derecho, que es la cavidad más anterior del corazón. Este presenta un tracto de salida largo, de trayectoria ascendente de adelante hacia atrás y hacia la izquierda que luego de la válvula pulmonar forma la arteria pulmonar principal o tronco de la pulmonar, que sigue la misma dirección, y al cruzar por delante del bronquio principal izquierdo se divide dando origen a las ramas izquierda y derecha.

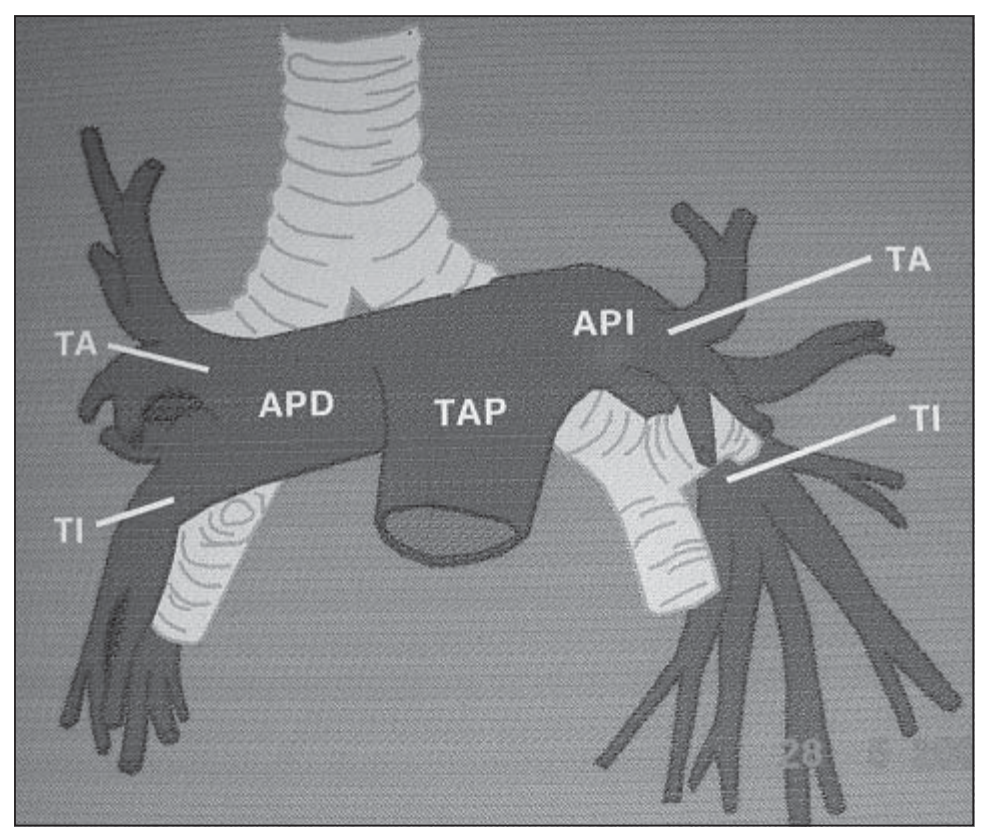

Figura 7. Sistema arterial pulmonar.

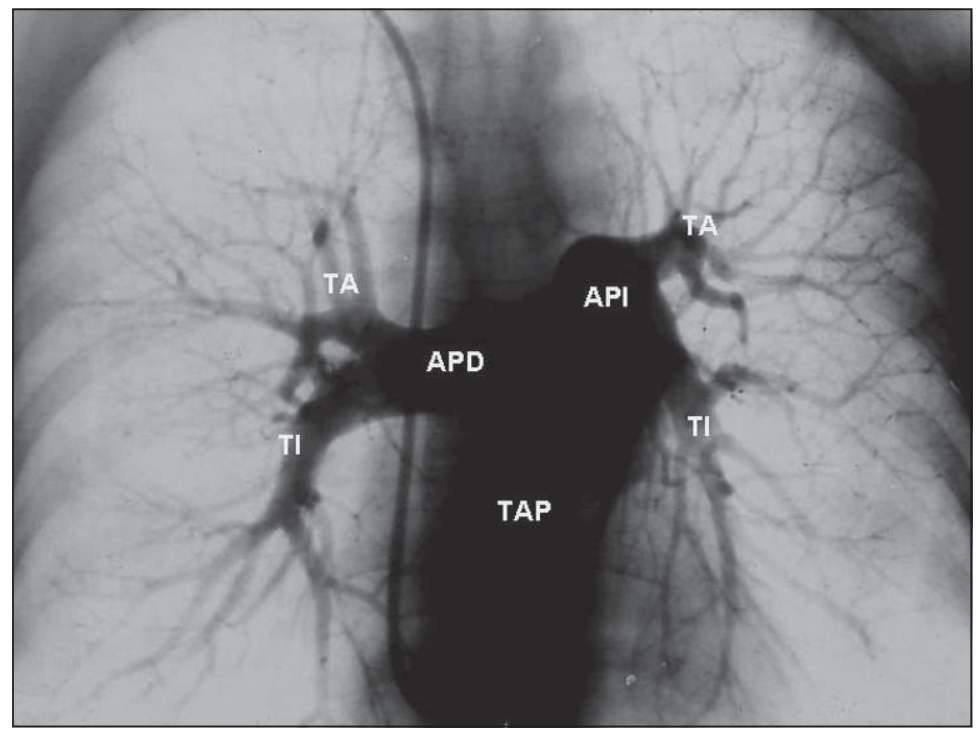

Figura 8a. Angiografía pulmonar frontal.

\begin{tabular}{|l|l|}
\hline \multicolumn{2}{|c|}{ Figuras 7, 8a y $\mathbf{8 b}$} \\
\hline TAP & Tronco de la arteria pulmonar \\
\hline APD & Arteria pulmonar derecha \\
\hline API & Arteria pulmonar izquierda \\
\hline TA & Tronco anterior \\
\hline TI & $\begin{array}{l}\text { Tronco inferior, descendente o } \\
\text { interlobar }\end{array}$ \\
\hline
\end{tabular}

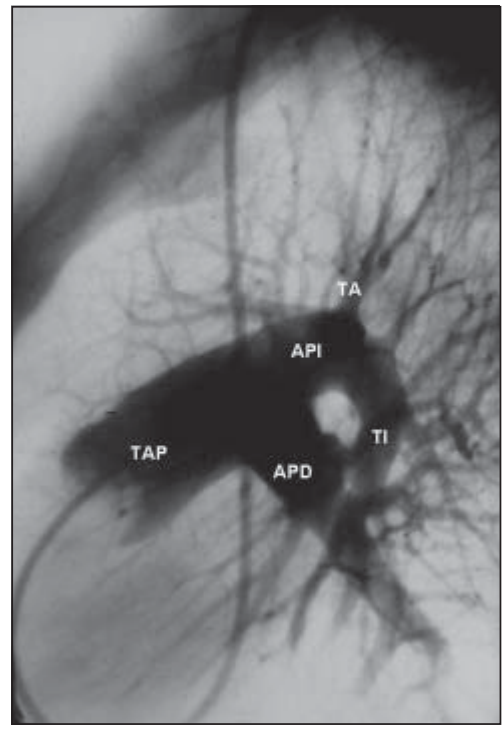

Figura 8b. Angiografía pulmonar lateral.

Rev Chil Enf Respir 2012; 28: 109-137 


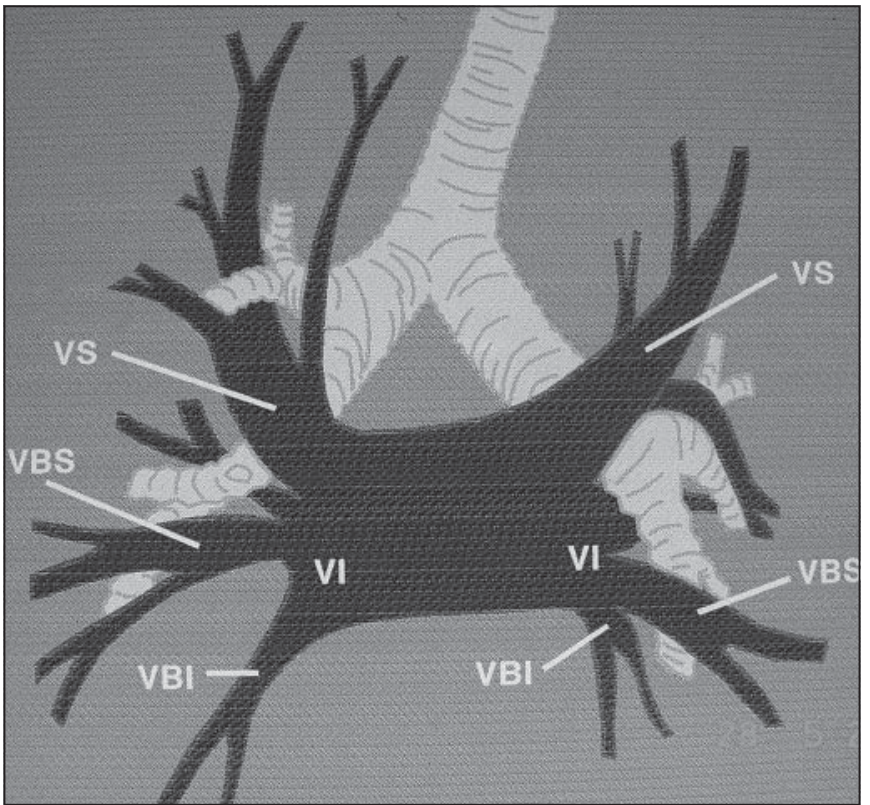

Figura 9. Sistema venoso pulmonar.

La rama izquierda es muy corta y continúa la misma trayectoria cabalgando sobre el sistema bronquial izquierdo formado por el principal, lobar superior y tronco ascendente (aspecto de silla de montar). En ese punto se divide en sus ramas: el tronco anterior que va a servir al lóbulo superior y la arteria interlobar, que desciende colocándose por detrás del sistema bronquial lobar inferior y que sirve a la língula y lóbulo inferior.

La arteria pulmonar derecha, a diferencia de la izquierda, es intramediastínica (por lo tanto invisible en la radiografía simple), cruzando en una trayectoria descendente de izquierda a derecha. A la altura del bronquio principal derecho da origen a sus ramas: el tronco anterior que aparece en la parte alta del hilio ramificándose para servir al lóbulo superior derecho y la arteria interlobar, la cual cruza por delante al bronquio intermedio circundándolo para ir a colocarse por fuera y discretamente por detrás e irrigar el lóbulo medio y lóbulo inferior.

\section{Sistema venoso pulmonar (Figuras 9 10a y 10b)}

Existen dos grandes troncos colectores a cada lado que desembocan en la aurícula izquierda, el tronco venoso superior y el tronco basal.

El tronco basal practicamente se divide inmediatamente en dos venas basales, la superior y la inferior. El tronco venoso superior es más largo (visible formando parte de la anatomía hiliar); en el lado derecho cruza por delante de la arteria interlobar y del sistema bronquial intermedio, dirigiéndose hacia arriba pasando en el ángulo forma-

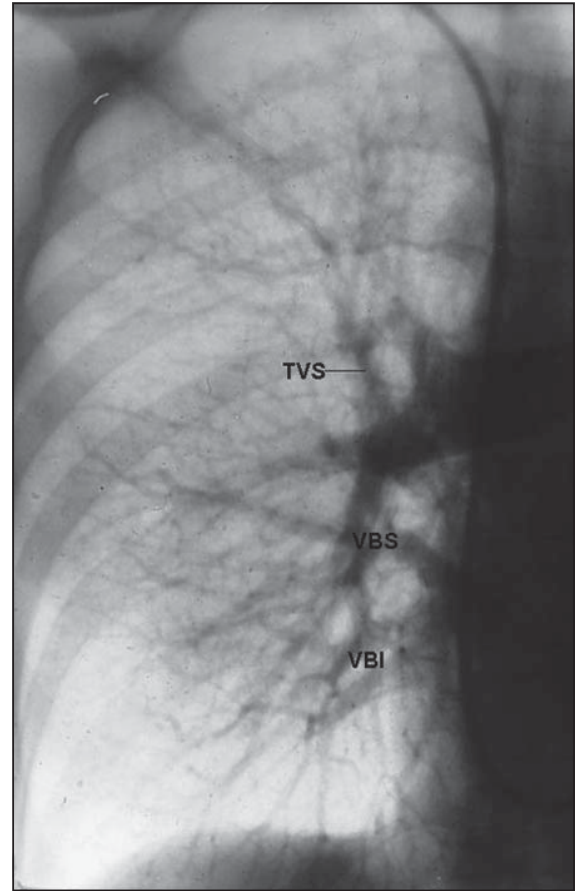

Figura 10a. Angiografía pulmonar frontal.

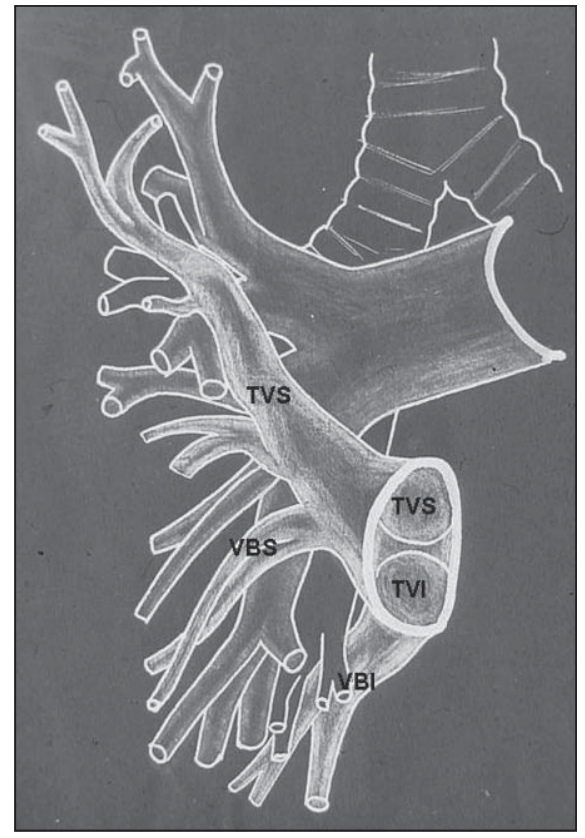

Figura 10b. Sistema venoso en relación con bronquios y arterias.

\begin{tabular}{|l|l|}
\hline \multicolumn{2}{|c|}{ Figuras 9, 10a y 10b } \\
\hline TVS & Tronco venoso superior \\
\hline TVI & Tronco venoso inferior \\
\hline VBS & Vena basal superior \\
\hline VBI & Vena basal inferior \\
\hline
\end{tabular}


do por los bronquios segmentarios anterior y posterior del lóbulo superior para recibir el aporte venoso del lóbulo superior. En el lado izquierdo el tronco venoso superior cruza por delante del bronquio lobar superior para recoger el sistema venoso lobar superior.

La distribución vascular pulmonar en los lóbulos superiores es la siguiente: En el lado derecho las venas se disponen por fuera de las arterias en trayectoria vertical. En el izquierdo sin embargo, en general se colocan por dentro del sistema arterial, aunque puede en algunas ocasiones ser externo. En las bases el sistema venoso lleva una dirección horizontal, a diferencia del sistema arterial que lleva una dirección vertical, siendo más fácil poder distinguir cuales son venas o arterias. Hay que considerar que normalmente en la Rx de pie, las venas superiores son muy poco visibles, por su bajo contenido de sangre, debido a su baja presión por efecto de la gravead. Cuando se hacen visibles por reclutamiento hay que sospechar procesos que implican hipertensión venosa pulmonar.

\section{Estructura pulmonar}

Es importante considerar algunos hechos estructurales básicos que van a tener una gran influencia en la formación de la imagen radiológica y manifestación de procesos patológicos.

Muchas de las estructuras que se mencionan a continuación, normalmente son invisibles en la radiografía de tórax, pero al ser afectados por los procesos patológicos se engruesan haciéndose visibles.

El pulmón derecho se encuentra dividido en tres lóbulos: el superior, medio e inferior, por dos cisuras la oblicua o mayor y la horizontal o menor (Figuras 4a y 11a). El izquierdo se divide en dos lóbulos el superior y el inferior por una cisura mayor $\mathrm{u}$ oblicua (Figu$\operatorname{ras} 4 b$ y $11 b)$.
La cisura oblicua izquierda llega muy alto, prácticamente a la altura del $4^{\circ}$ ó $5^{\circ}$ arco costal posterior, dirigiéndose hacia abajo y adelante para terminar en el tercio anterior del hemidiafragma. La derecha, sin embargo, es más baja y menos declive, originándose a la altura del $6^{\circ}$ arco costal posterior y también terminando en el tercio anterior del hemidiafragma. La menor se origina desde la mayor en disposición horizontal hacia adelante.

Los lóbulos se dividen en segmentos, subsegmentos y finalmente en lobulillos, los que pueden o no estar separados por tabiques. Del punto de vista de la correlación radiológicaanatomopatológica, nos interesa identificar los lóbulos, los segmentos y de allí nos saltamos al lobulillo y acino pulmonar. Los subsegmentos no ofrecen ventaja en esta correlación.

El lóbulo, segmento, subsegmento y lobulillo pulmonar tienen una forma piramidal, donde los bronquios y arteria se disponen en el centro y las venas en la periferia (Figura 12).

\section{Segmentación pulmonar (Figuras 4a, 4b, 11a y 11b)}

Como los segmentos no están separados por tabiques, sus límites son imprecisos y por supuesto no están delimitados, por esto nos tenemos que valer de dos puntos de referencia para
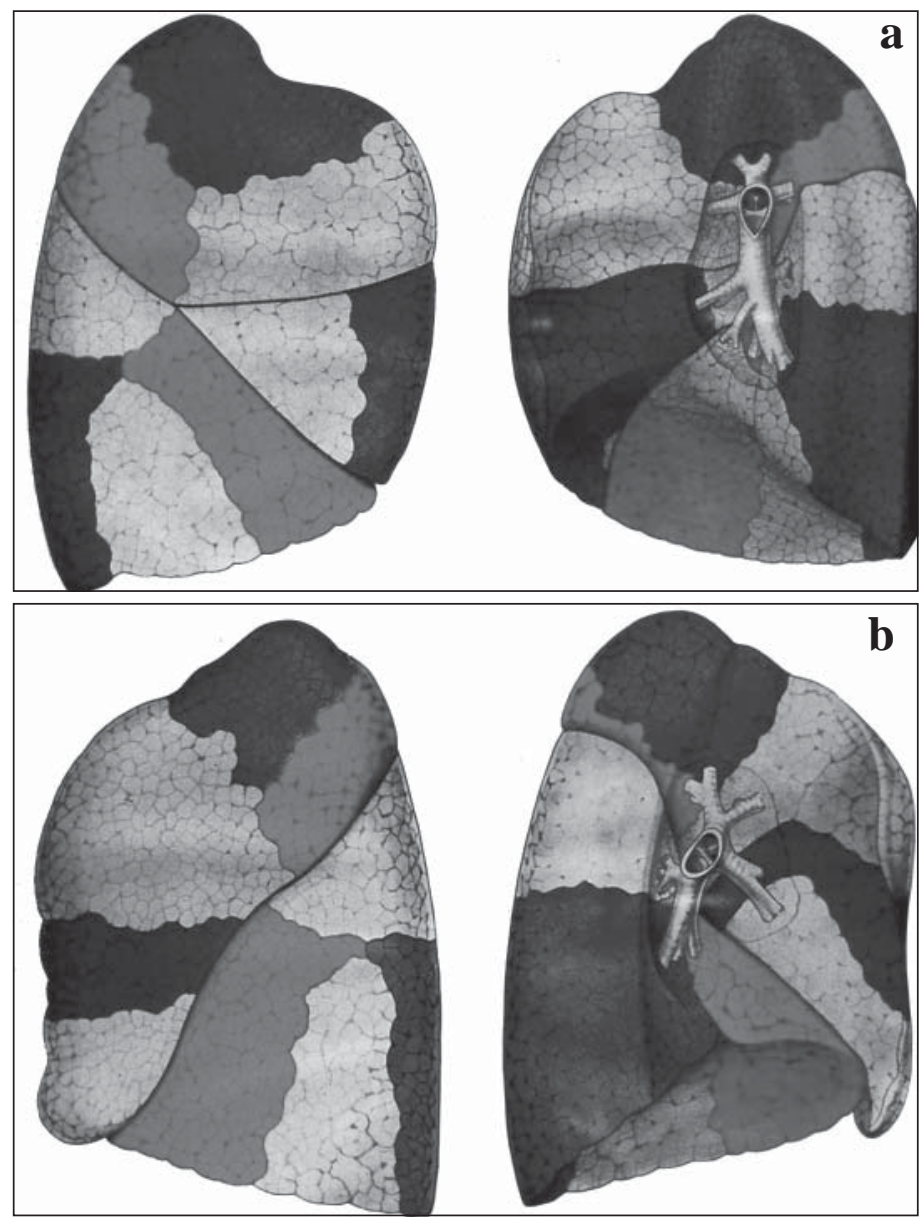

Figura 11. Esquema de las cisuras y segmentación pulmonar. a) pulmón derecho, b) izquierdo. 


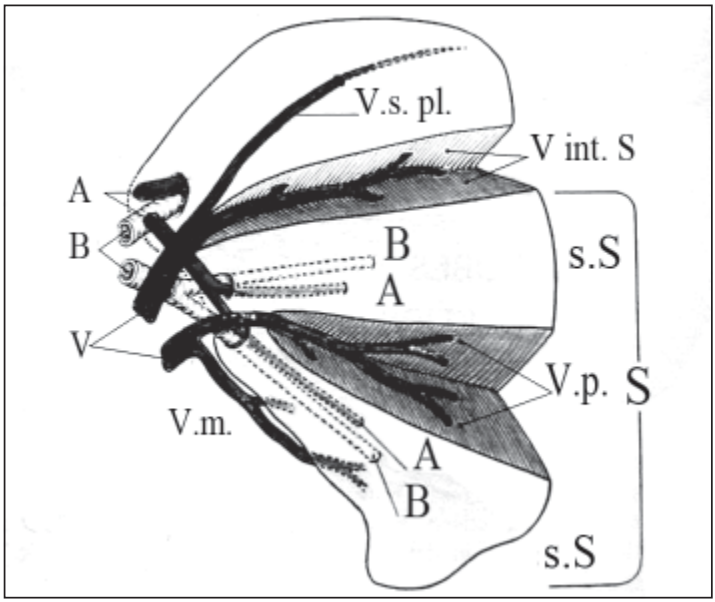

Figura 12. Esquema del lóbulo, segmento y subsegmento pulmonar: A: Arteria. B: Bronquio. V: Vena pulmonar. VsPL; vena sub pleural. Vint S; Vena ínter segmentaría. Vp; Vena intrapulmonar. S: Segmento. s.S: subsegmento.

determinar su posición, considerando además su forma piramidal con el vértice hacia el hilio lobar y la base hacia la pleura. La primera referencia son las cisuras que separan los lóbulos y la segunda referencia son los ejes bronco vasculares segmentarios, que transcurren por el centro del segmento. Así en la radiografía de tórax frontal y lateral, debemos observar la posición de las cisuras delimitando el lóbulo y la distribución bronquial segmentaria, localizando de esta forma aproximada los límites de los segmentos.

Lóbulo superior derecho: Segmento apical hacia arriba ocupando el vértice. Segmento anterior hacia delante con base en la pared anterior y delimitada por la cisura menor. El segmento posterior hacia atrás de base en la pared posterior y delimitada por la parte alta de la cisura mayor.

Lóbulo medio: Segmento medial, contacta la pleura para cardiaca y la pleura diafragmática anterior. Segmento lateral, ocupa la región axilar, delimitada por la cisura menor por arriba y la cisura mayor por abajo y atrás.

Lóbulo inferior derecho: Segmento apical, ocupa el vértice por detrás de la cisura mayor (se relaciona por delante con el segmento posterior del lóbulo superior derecho), y contacta por detrás la pared torácica posterior. El segmento basal medial, es retrocisural mayor, pero no llega al diafragma (detrás del segmento medial del lóbulo medio). El segmento basal anterior, también es retro cisural mayor, más externo, llega hasta el diafragma y además ocupa la lengüeta costofrénica, contactando así la pared axilar. El segmento basal lateral es póstero-lateral, llega al diafragma, no ocupa la lengüeta costofrénica y sí contacta al diafragma. Finalmente el basal posterior, es retro cardiaco para espinal y contacta la pared posterior.

Lóbulo superior izquierdo: Segmento ápicoposterior ocupa topográficamente la equivalencia de los segmentos correspondientes derechos, pero sin la relación cisural menor. La língula ocupa la equivalencia del lóbulo medio, o sea paracardiaco, por delante de la cisura mayor inferior, pared torácica anterior y pleura diafragmática anterior.

Lóbulo inferior izquierdo: Segmento apical es igual que en el lado derecho. Segmento basalanteromedial, retro cisural mayor, contacta al diafragma y ocupa la lengüeta costofrénica. Basal lateral equivalente al del lado derecho y basal posterior también equivalente.

\section{El lobulillo pulmonar (Figuras 13 y 14)}

Por definición es la última porción de parénquima separada por tabiques. Mide aproximadamente de 1 a $2,5 \mathrm{~cm}$ y contiene de 2 a 5 acinos. Para algunos autores esta es la unidad respiratoria terminal utilizada para la correlación entre la radiología y la anatomo-patología. Sin embargo, si consideramos que por un lado su tamaño es muy variable y por otro que hacia el interior del parénquima hay muy poco desarrollo de tabiques resulta generalmente muy difícil identificar e individualizar un trastorno lobulillar.

\section{El acino pulmonar (Figuras 15a y 15b)}

Es la última porción de parénquima distal al bronquíolo terminal y por lo tanto está formada por bronquíolos respiratorios, conductos alveolares, sacos alveolares y por alvéolos. Este mide aproximadamente 7,5 a $8,5 \mathrm{~mm}$. El acino es para otros autores la unidad respiratoria terminal, ya que es radiológicamente visible cuando se condensa, de tamaño regular y se puede identificar en cualquier parte de pulmón.

Los alvéolos (Figura 16) tienen una forma poliédrica irregular y miden entre 100 y $300 \mu \mathrm{m}$, y por supuesto son invisibles en la Rx de tórax.

Además de la vía aérea canalicular, bronquiolar, existen vías colaterales de comunicación, no sólo de aire, sino también de procesos patológicos:

a) Poros de Kohn (Figuras 16 y 17): Son pequeñas ventanas en la pared de los alvéolos, tapizadas de epitelio alveolar, comunicando el espacio aéreo de uno y otro alvéolo, que pueden pertenecer al mismo acino o a acinos vecinos (ya que no existen tabiques).

b) Canales de Lambert (Figura 18): Comunican bronquíolo terminal y respiratorio con alvéolos vecinos y están tapizados por epitelio bronquiolar.

c) Comunicaciones interbronquiolares. 


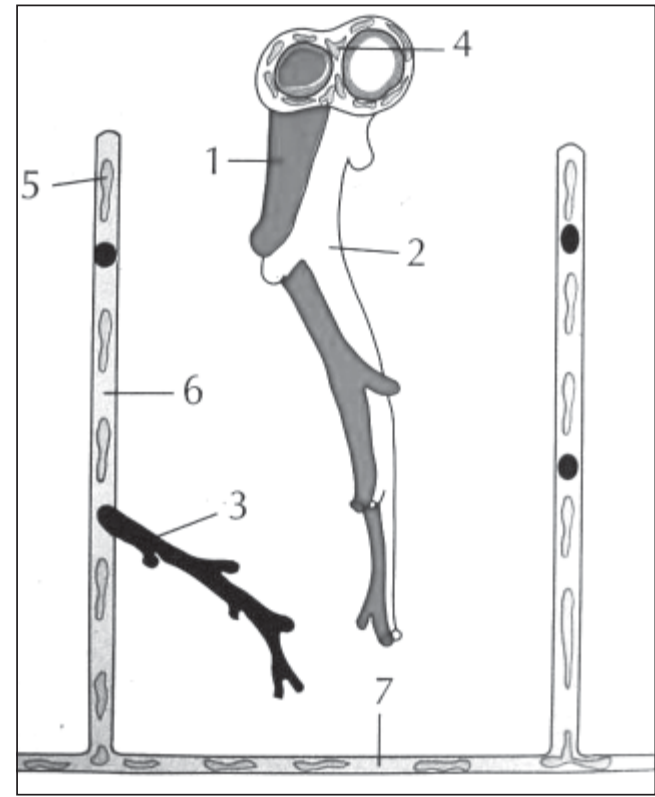

Figura 13. Esquema lobulillo pulmonar. 1) Arteria pulmonar. 2) Bronquio. 3) Vena pulmonar. 4) Vaso linfático en el conectivo linfático peribronco-vascular. 5) Vaso linfático en el conectivo periférico. 6) Tabique perilobulillar. 7) Conectivo subpleural.

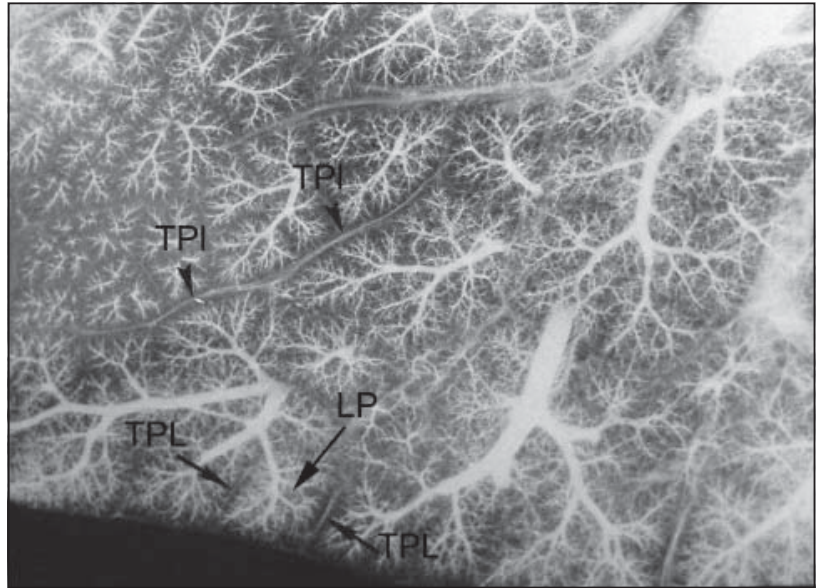

Figura 14. Corte de pulmón con contraste en las arterias pulmonares. Los bronquios transcurren adyacentes. CSP: conectivo subpleural del que se originan los tabiques perilobulillares (TPL), (líneas de Kerley B.), que separan los lobulillos pulmonares (LP). Hay tabiques largos (TPl) en el interior del pulmón (líneas de Kerley A).
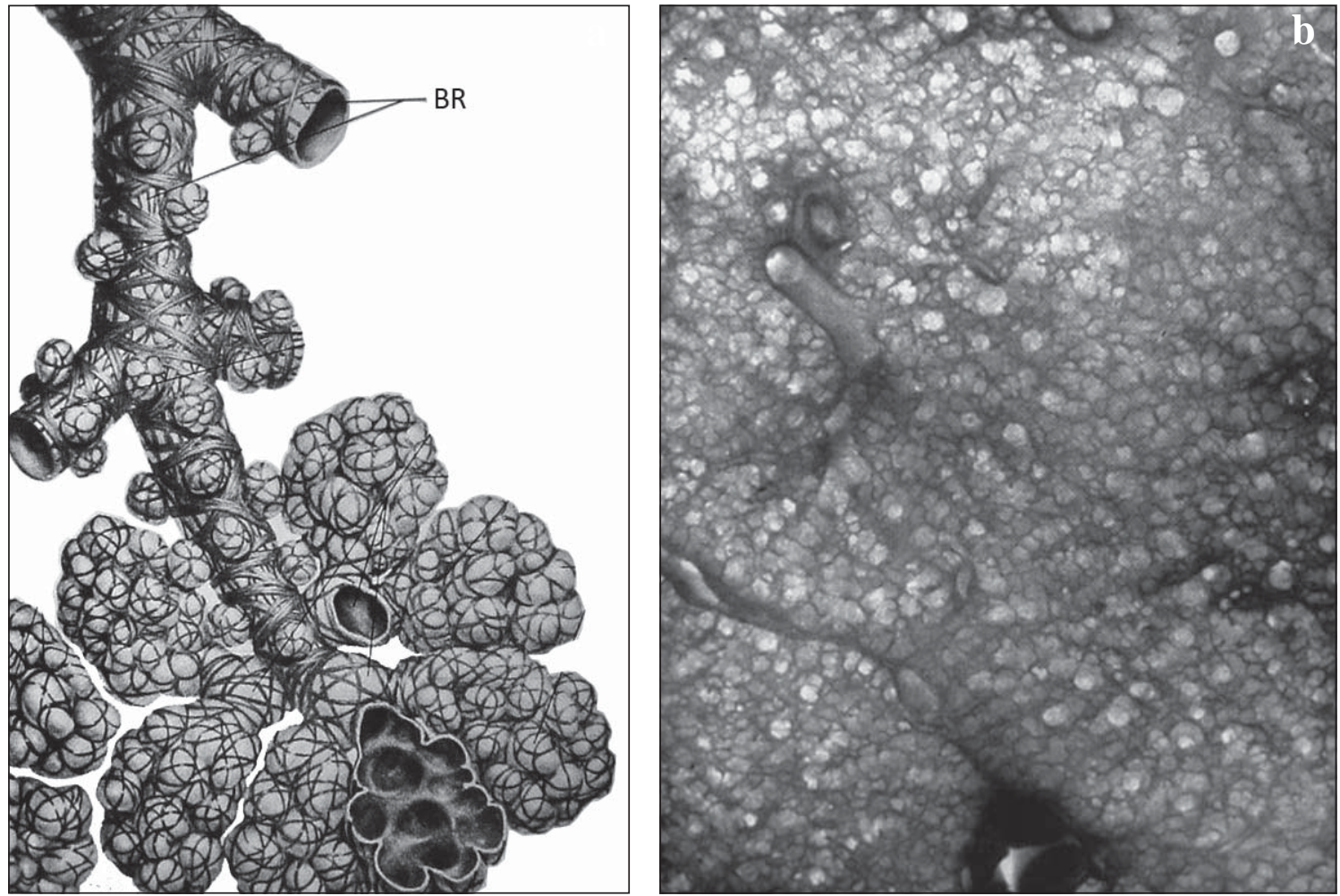

Figura 15. a) Esquema del acino pulmonar que se origina distal al bronquiolo terminal. Luego se originan los bronquiolos respiratorios (BR). b) Fotografía de parénquima pulmonar, que muestra bronquiolos terminales inmersos en parénquima alveolizado, no existen tabiques entre los acinos. 


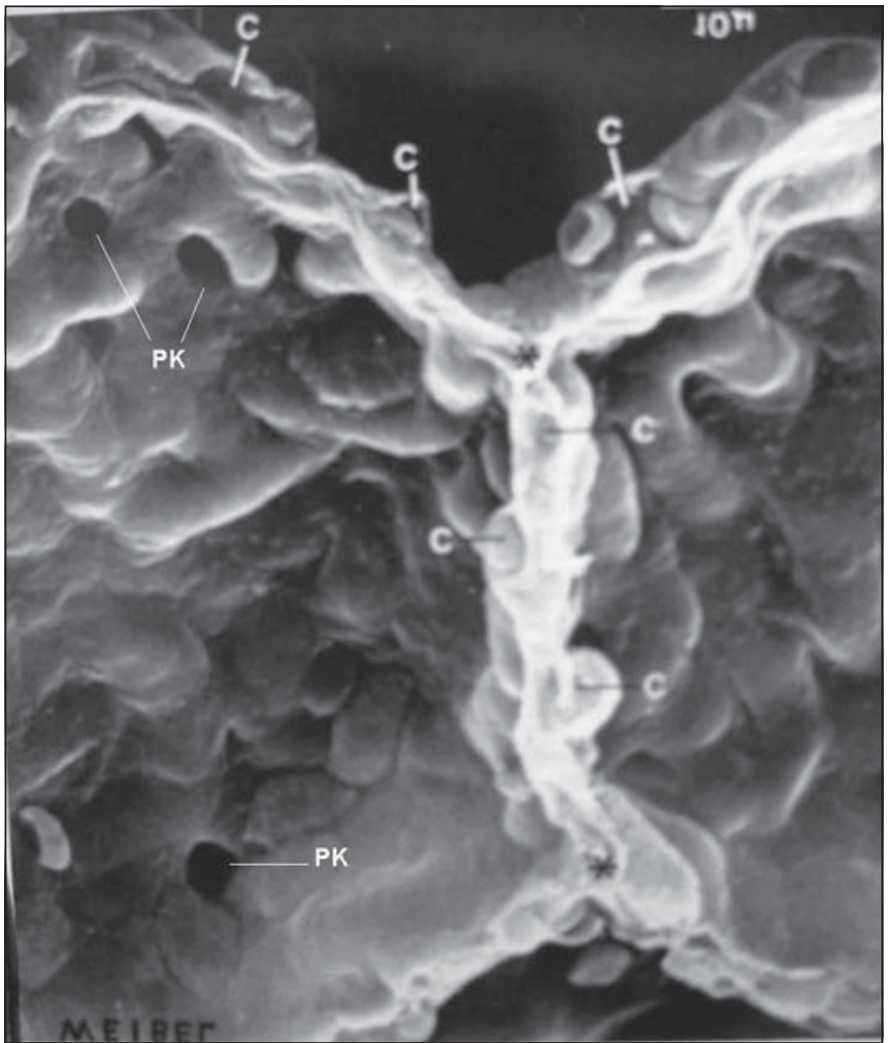

Figura 16. Alvéolos. Forma poliédrica donde se observan los capilares (c), serpenteando de un lado a otro por los tabiques. Poros de Kohn (PK).

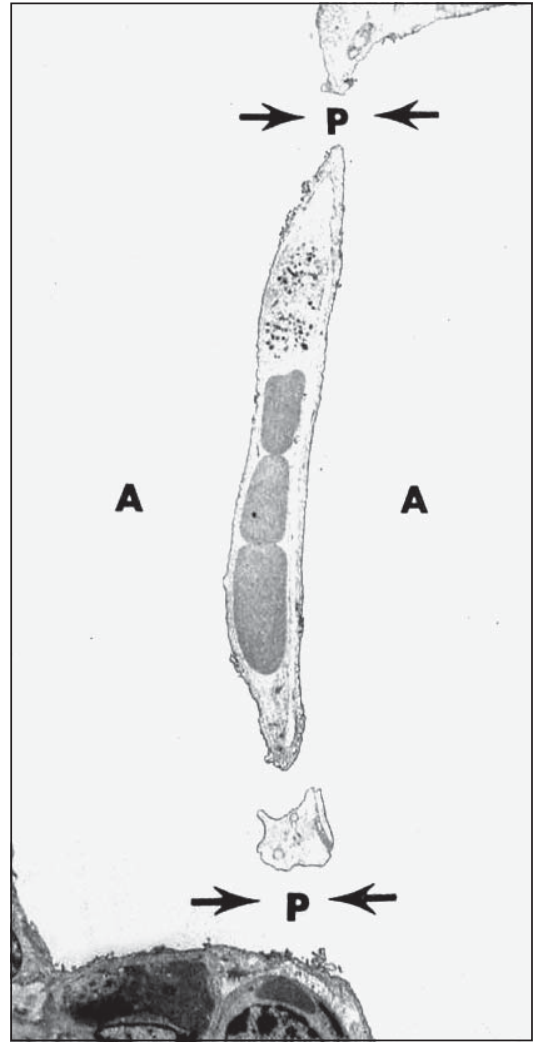

Figura 17. Pared alveolar, mostrando las comunicaciones a través de los poros de Kohn (P).

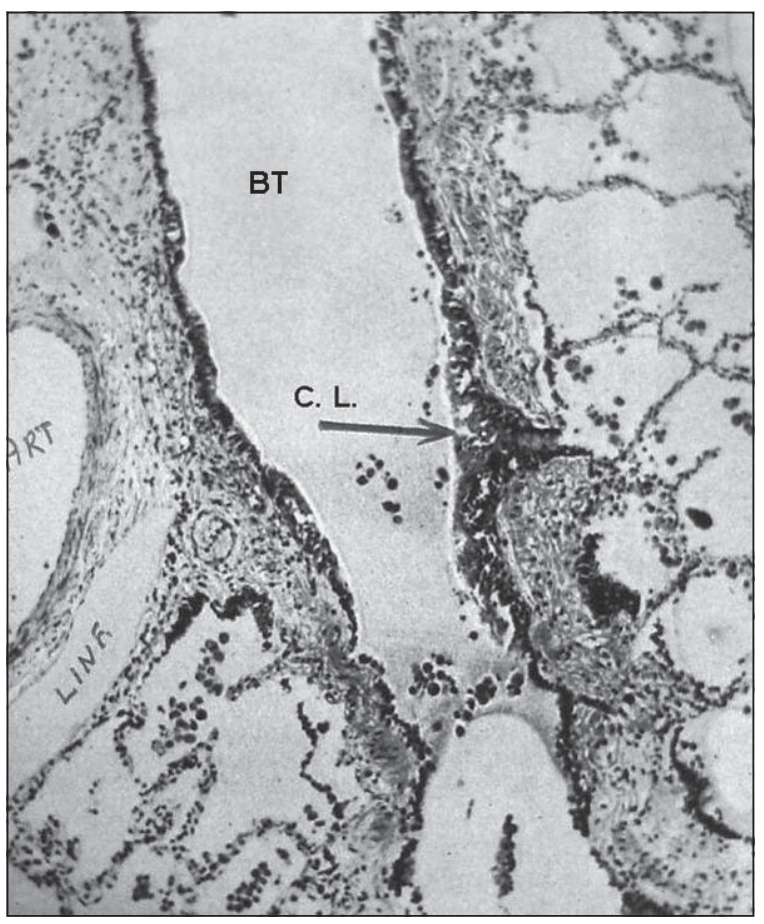

Figura 18. Bronquiolo terminal (BT); Comunicaciones al parénquima vecino a través de canales de Lambert (C.L.).

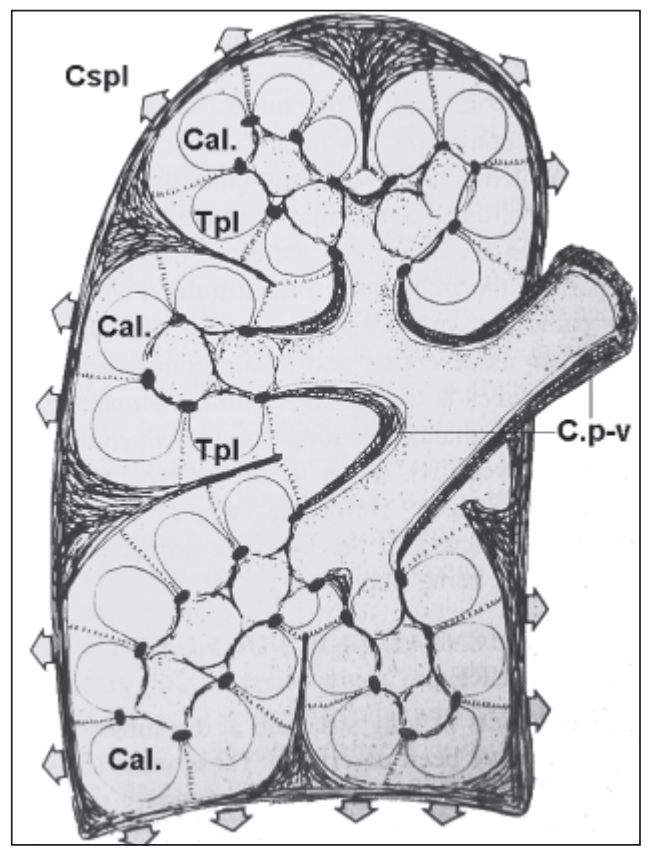

Figura 19. Esquema del conectivo linfático; Peribronco-vascular (C.p-v), y periférico; subpleural (Cspl) y de los tabiques perilobulillares $(\mathrm{Tpl})$. Entre ambos está el conectivo alveolar (Cal). 


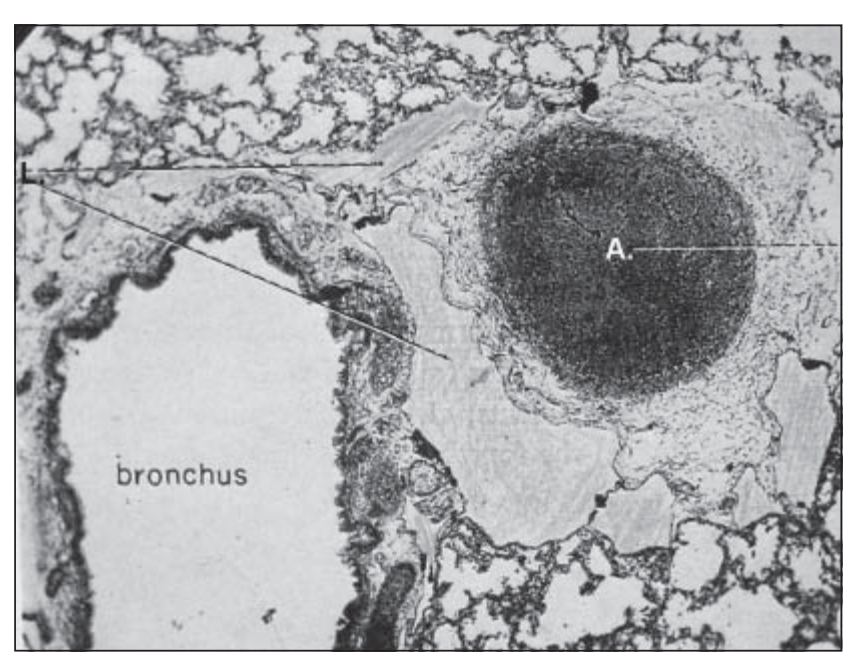

Figura 20. Corte de la pareja bronco-arterial; rodeado por conectivo linfático. Lagos linfáticos (L).

\section{Intersticio pulmonar}

El intersticio pulmonar se divide en dos compartimentos principales según si contienen o no vasos linfáticos en su interior:

1) Conectivo linfático (Figuras 13 y 19): Contiene vasos linfáticos en su interior y sirve de soporte y conducción de líquidos. Se subdivide en:

a Conectivo peribronco-vascular o axial (Figura 20): Este forma las vainas peribronco-vasculares en el centro del acino y lobulillo.

b. Conectivo periférico (Figura 21): Corresponde al conectivo sub-pleural y de los tabiques perilobulillares, en la periferia del lobulillo.

Estos dos subgrupos del conectivo linfático, no se comunican entre ellos y están separados por el conectivo alveolar.

2) Conectivo alveolar (Figura 22). Corresponde a la pared alveolar, que no contiene linfáticos en su interior y está formado por un eje fino de tejido conectivo por el cual serpentean los capilares pulmonares tomando contacto con el aire dentro de uno y otro espacio alveolar. Esta pared alveolar tiene una porción delgada y una gruesa. En la primera, la membrana basal del epitelio alveolar y del endotelio capilar está fusionada, produciéndose el intercambio gaseoso. En la segunda, las membranas basales están separadas por sustancia fundamental, produciéndose a través de ella el intercambio acuoso.

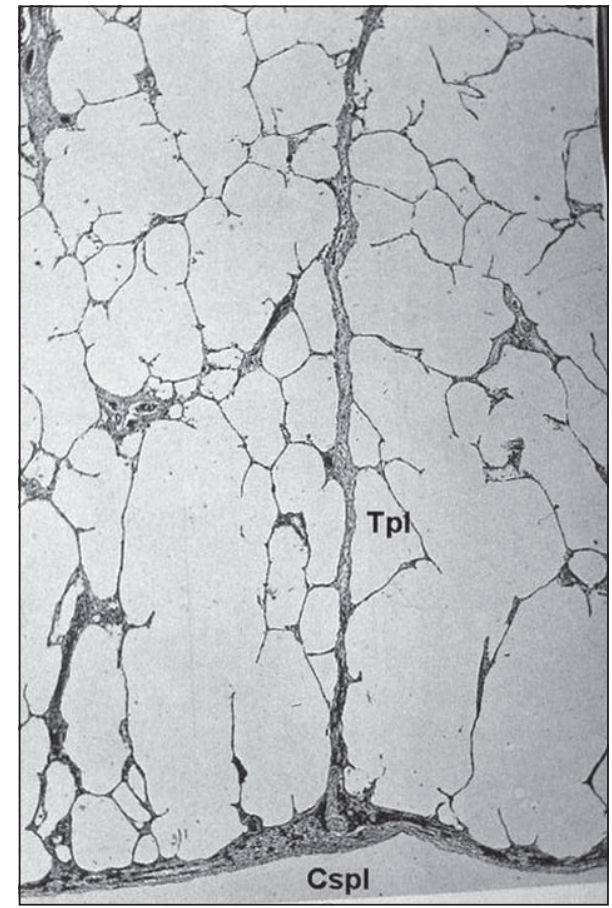

Figura 21. Tabiques perilobulillares (Tpl), que se derivan del conectivo subpleural (Cspl), ambos parte del conectivo linfático periférico.

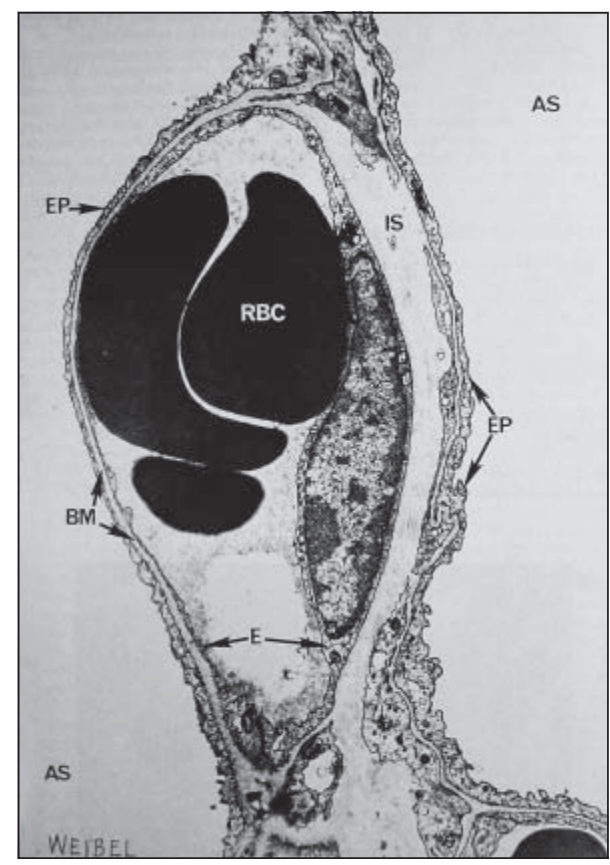

Figura 22. Pared alveolar. EP; Epitelio alveolar. E; Endotelio capilar. BM; Membrana basal. 


\section{Atlas tomográfico del tórax}

\section{Árbol Traqueo bronquial}

\begin{tabular}{|l|l|}
\hline $\mathbf{T}$ & Tráquea \\
\hline $\mathbf{C}$ & Carina \\
\hline ESC & Espacio subcarinal \\
\hline RAE & Receso ácigo-esofágico \\
\hline BA & Botón aórtico \\
\hline $\mathbf{1}$ & Bronquio principal derecho \\
\hline $\mathbf{2}$ & Bronquio principal izquierdo \\
\hline $\mathbf{3}$ & Bronquio lobar superior derecho \\
\hline $\mathbf{4}$ & $\begin{array}{l}\text { Bronquio lobar superior izquierdo } \\
\text { a. Tronco ascendente } \\
\text { b. Tronco descendente o lingular }\end{array}$ \\
\hline $\mathbf{5}$ & Bronquio intermedio \\
\hline $\mathbf{6}$ & Bronquio lobar inferior derecho \\
\hline $\mathbf{7}$ & Bronquio lobar inferior izquierdo \\
\hline $\mathbf{8}$ & Bronquio lobar medio \\
\hline
\end{tabular}

\begin{tabular}{|r|l|}
\hline $\mathbf{9}$ & Bronquio segmentario anterior \\
\hline $\mathbf{1 0}$ & Bronquio segmentario posterior \\
\hline $\mathbf{1 1}$ & Bronquio segmentario apical \\
\hline $\mathbf{1 2}$ & Bronquio segmentario ápico-posterior \\
\hline $\mathbf{1 3}$ & Bronquio lingular superior \\
\hline $\mathbf{1 4}$ & Bronquio lingular inferior \\
\hline $\mathbf{1 5}$ & Bronquio segmentario medial \\
\hline $\mathbf{1 6}$ & Bronquio segmentario lateral \\
\hline $\mathbf{1 7}$ & Bronquio segmentario apical del lóbulo inferior \\
\hline $\mathbf{1 8}$ & Bronquio segmentario basal medial \\
\hline $\mathbf{1 9}$ & Bronquio segmentario basal anterior \\
\hline $\mathbf{2 0}$ & Bronquio segmentario basal antero-medial \\
\hline $\mathbf{2 1}$ & Bronquio segmentario basal lateral \\
\hline 22 & Bronquio segmentario basal posterior \\
\hline
\end{tabular}
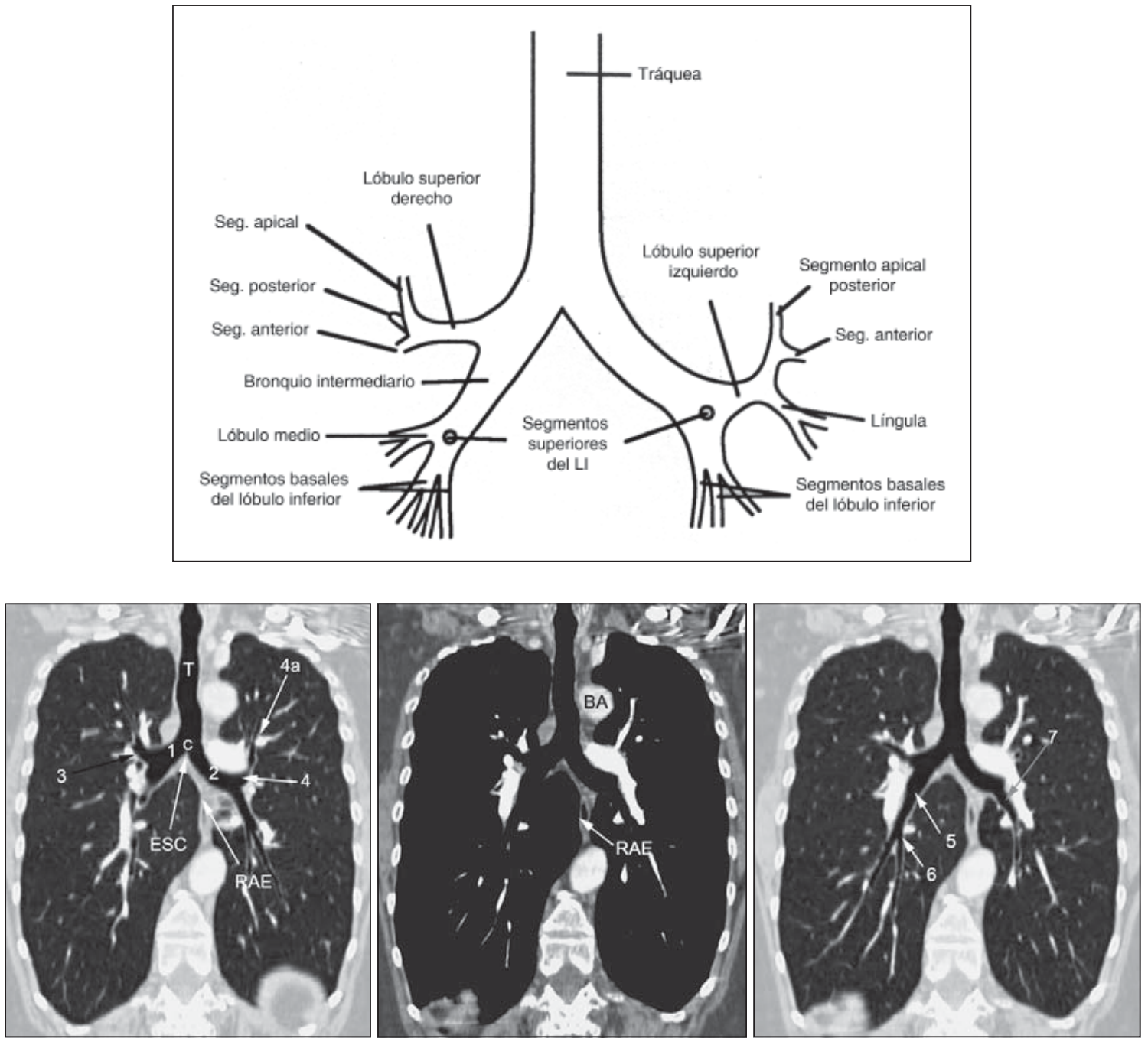

Rev Chil Enf Respir 2012; 28: 109-137 


\begin{tabular}{|l|l|}
\hline $\mathbf{T}$ & Tráquea \\
\hline $\mathbf{C}$ & Carina \\
\hline ESC & Espacio subcarinal \\
\hline RAE & Receso ácigo-esofágico \\
\hline BA & Botón aórtico \\
\hline $\mathbf{1}$ & Bronquio principal derecho \\
\hline $\mathbf{2}$ & Bronquio principal izquierdo \\
\hline $\mathbf{3}$ & Bronquio lobar superior derecho \\
\hline $\mathbf{4}$ & $\begin{array}{l}\text { Bronquio lobar superior izquierdo } \\
\text { a. Tronco ascendente } \\
\text { b. Tronco descendente o lingular }\end{array}$ \\
\hline $\mathbf{5}$ & Bronquio intermedio \\
\hline $\mathbf{6}$ & Bronquio lobar inferior derecho \\
\hline $\mathbf{7}$ & Bronquio lobar inferior izquierdo \\
\hline $\mathbf{8}$ & Bronquio lobar medio \\
\hline & \multicolumn{2}{|l}{} \\
\hline
\end{tabular}

\begin{tabular}{|r|l|}
\hline $\mathbf{9}$ & Bronquio segmentario anterior \\
\hline $\mathbf{1 0}$ & Bronquio segmentario posterior \\
\hline $\mathbf{1 1}$ & Bronquio segmentario apical \\
\hline $\mathbf{1 2}$ & Bronquio segmentario ápico-posterior \\
\hline $\mathbf{1 3}$ & Bronquio lingular superior \\
\hline $\mathbf{1 4}$ & Bronquio lingular inferior \\
\hline $\mathbf{1 5}$ & Bronquio segmentario medial \\
\hline $\mathbf{1 6}$ & Bronquio segmentario lateral \\
\hline $\mathbf{1 7}$ & Bronquio segmentario apical del lóbulo inferior \\
\hline $\mathbf{1 8}$ & Bronquio segmentario basal medial \\
\hline $\mathbf{1 9}$ & Bronquio segmentario basal anterior \\
\hline $\mathbf{2 0}$ & Bronquio segmentario basal antero-medial \\
\hline $\mathbf{2 1}$ & Bronquio segmentario basal lateral \\
\hline 22 & Bronquio segmentario basal posterior \\
\hline
\end{tabular}

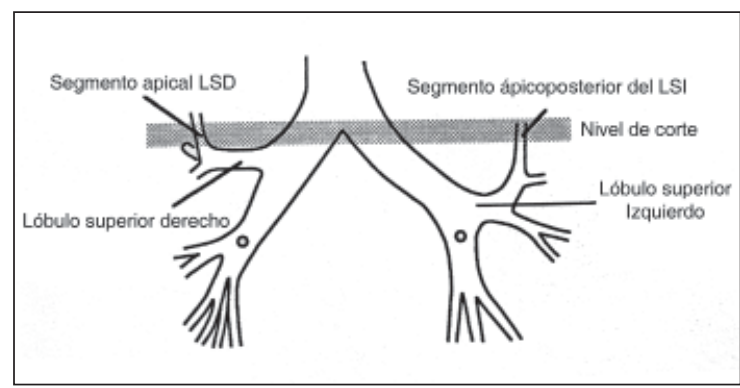

A

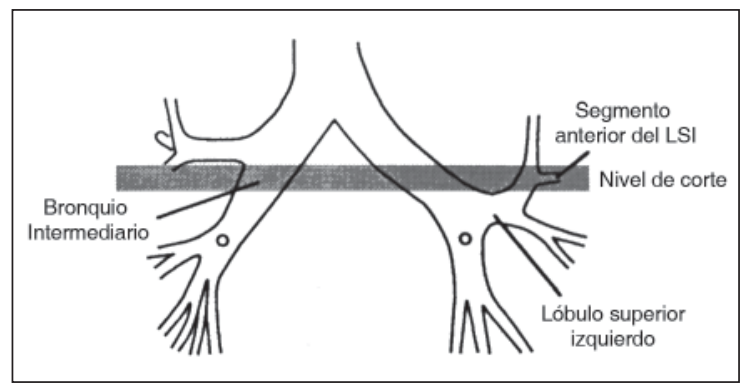

C

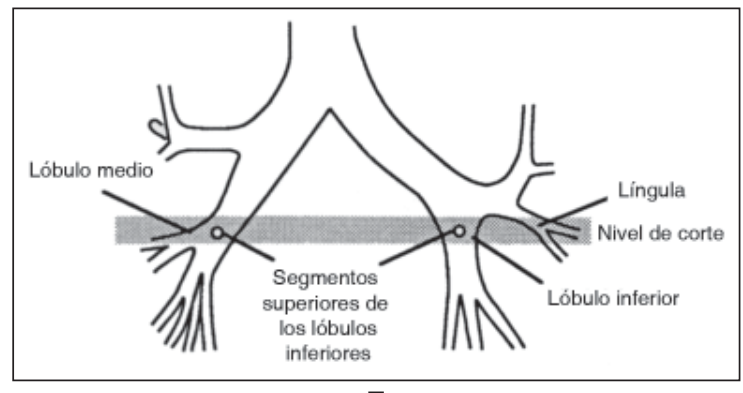

E

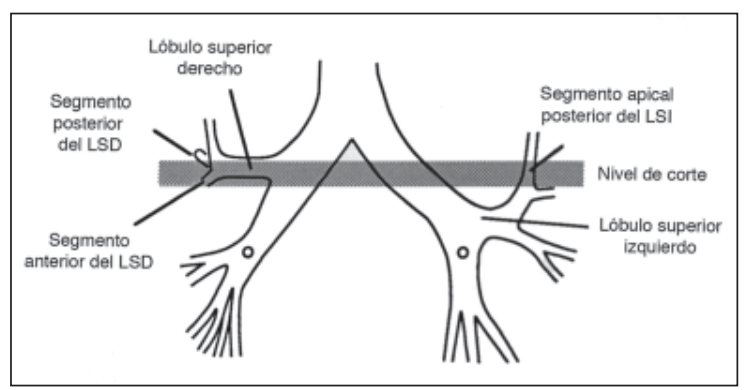

B

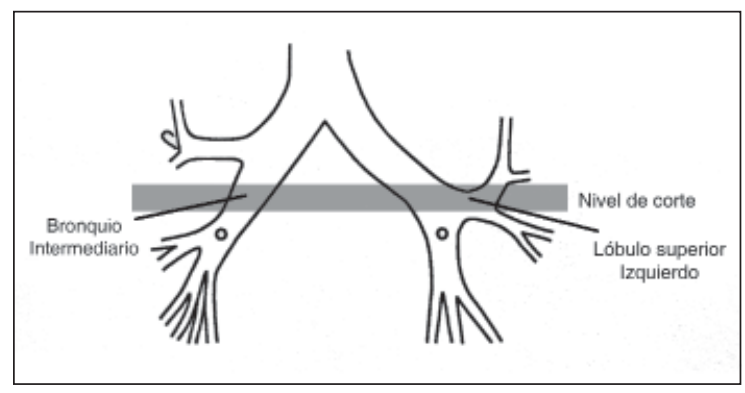

D

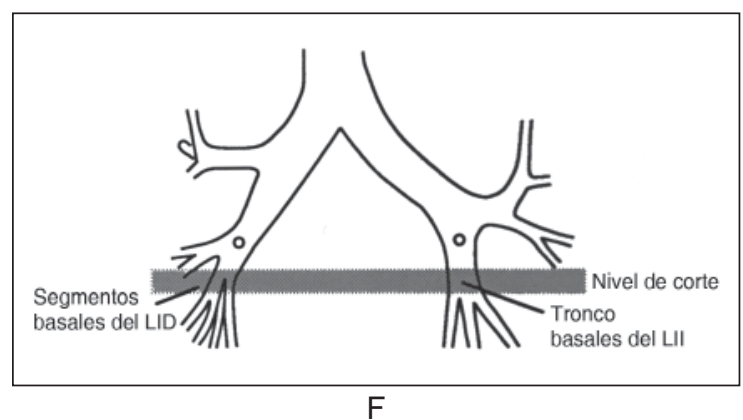

F 
ATLAS TOMOGRÁFICO DEL TÓRAX
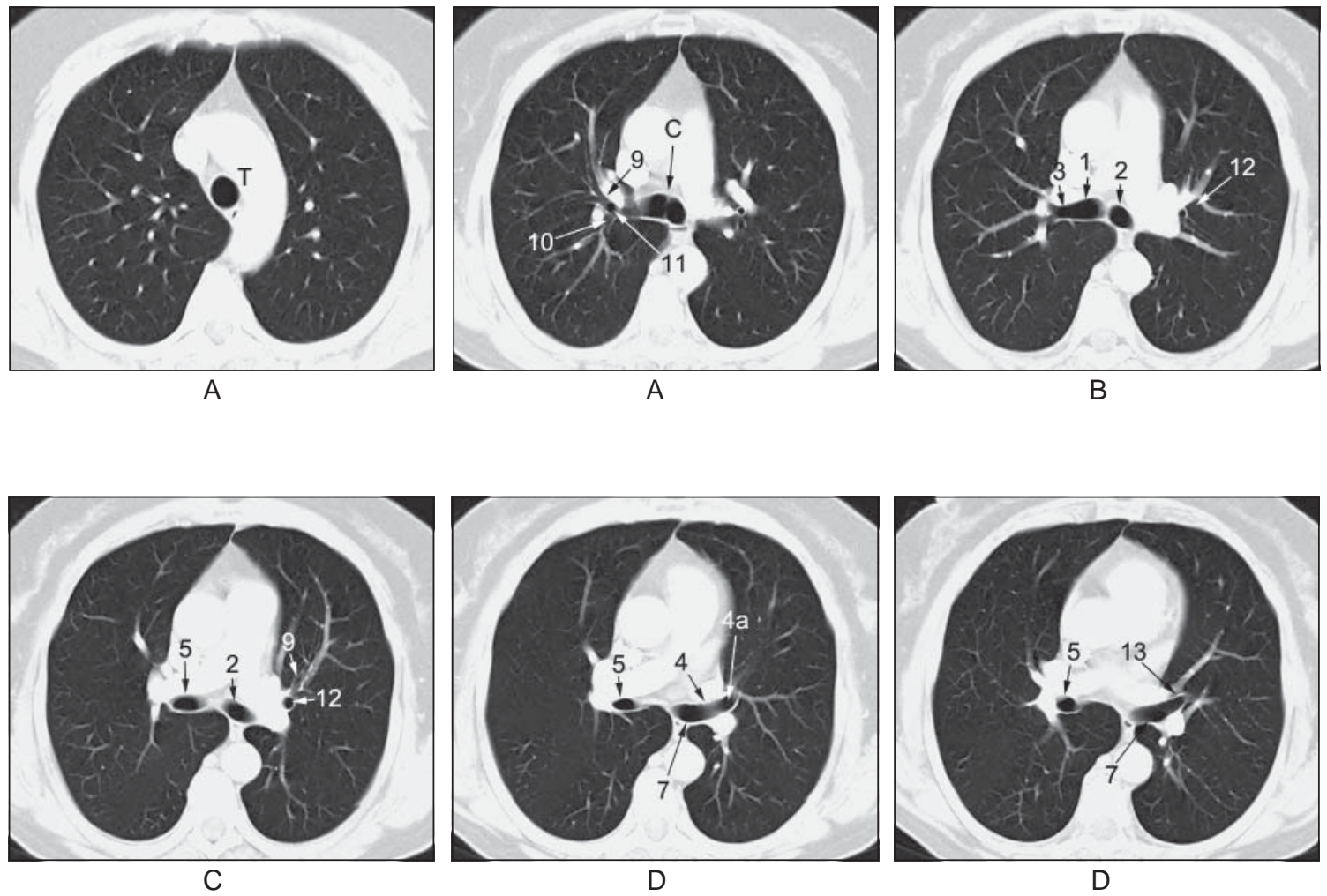

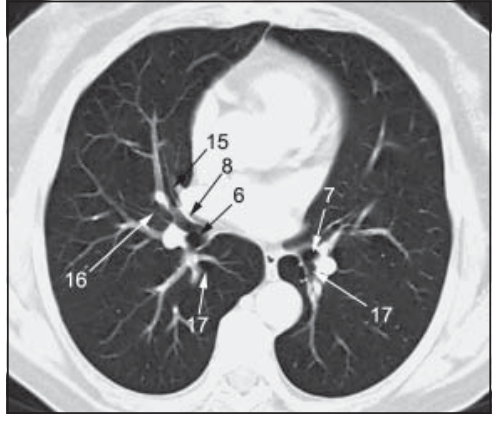

E

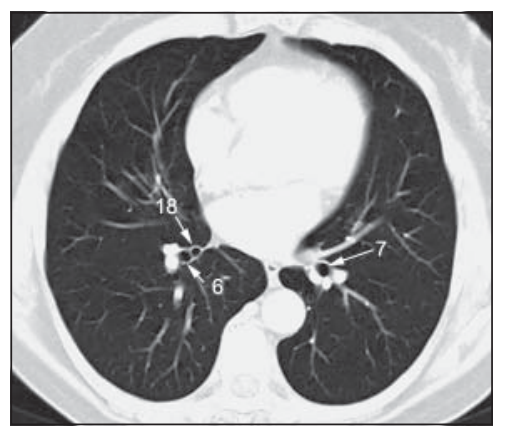

$\mathrm{F}$

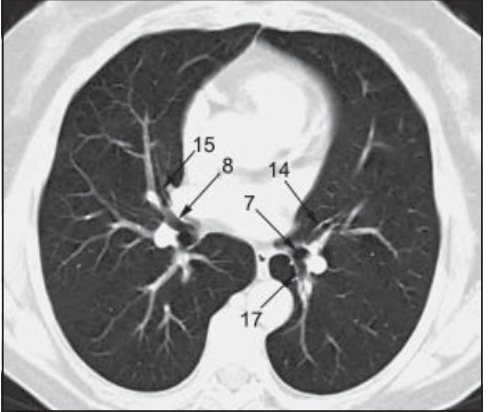

E

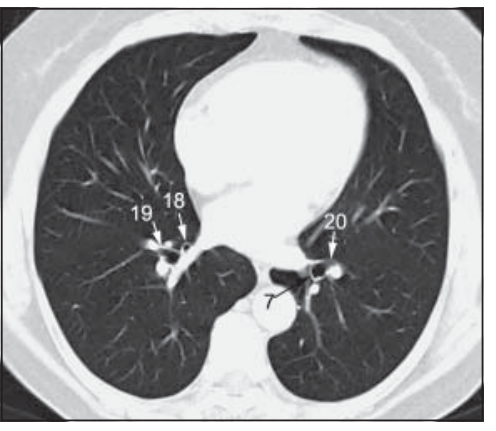

$\mathrm{F}$

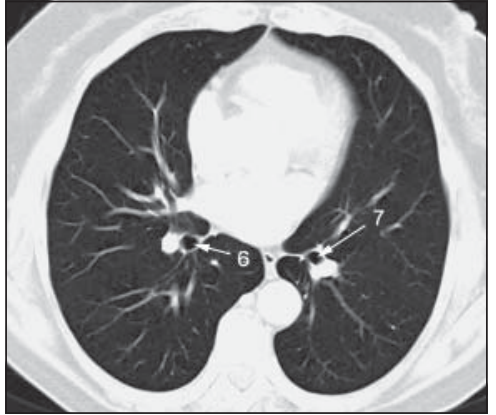

F

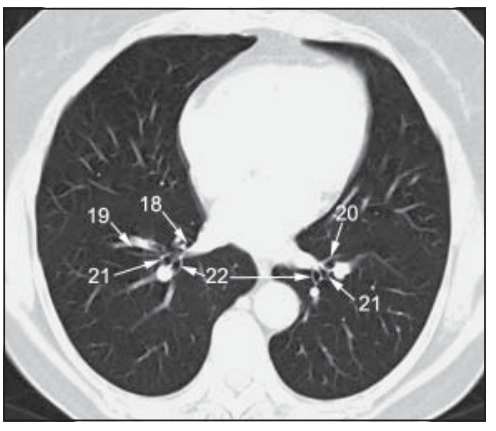




\section{Vascularización pulmonar}

\begin{tabular}{|l|l|}
\hline Ao & Aorta \\
\hline RAo & Raíz aórtica \\
\hline VD & Ventrículo derecho \\
\hline VI & Ventrículo izquierdo \\
\hline AI & Aurícula izquierda \\
\hline
\end{tabular}$\quad$\begin{tabular}{rlll|}
\hline $\mathbf{1}$ & Tracto de salida del ventrículo derecho \\
\hline $\mathbf{2}$ & Tronco de la arteria pulmonar \\
\hline $\mathbf{3}$ & Rama izquierda de la arteria pulmonar \\
\hline $\mathbf{4}$ & Tronco arterial ascendente \\
\hline $\mathbf{5}$ & Tronco arterial descendente o interlobar izquierdo \\
\hline $\mathbf{6}$ & Rama derecha de la arteria pulmonar \\
\hline
\end{tabular}
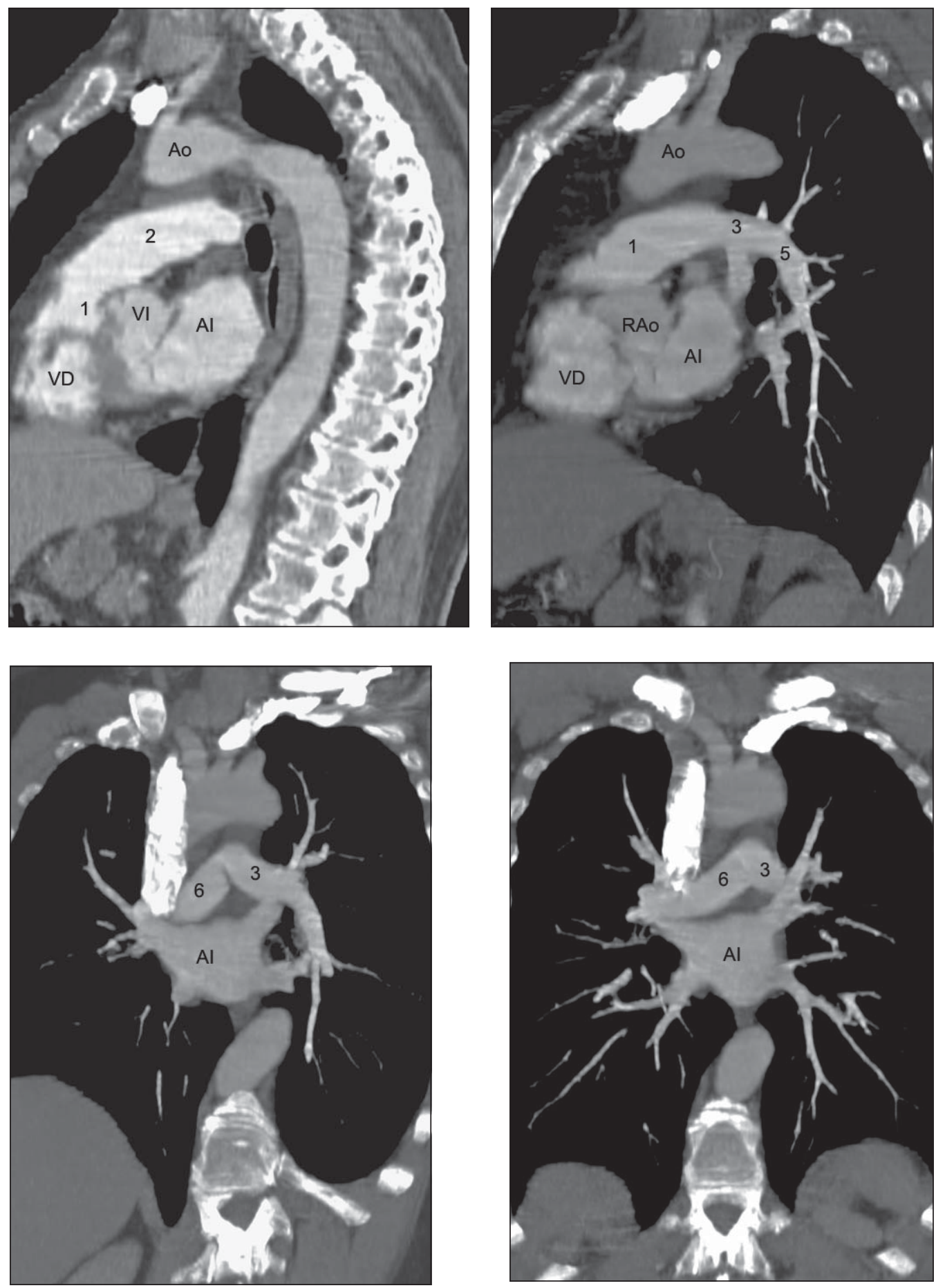


\begin{tabular}{|l|l|}
\hline RAo & Raíz aórtica \\
\hline AD & Aurícula derecha \\
\hline AI & Aurícula izquierda \\
\hline AoD & Aorta descendente \\
\hline AoA & Aorta ascendente \\
\hline VD & Ventrículo derecho \\
\hline VI & Ventrículo izquierdo \\
\hline $\mathbf{1}$ & $\begin{array}{l}\text { Tracto salida del ventrículo } \\
\text { derecho }\end{array}$ \\
\hline $\mathbf{2}$ & $\begin{array}{l}\text { Tronco de la arteria pul- } \\
\text { monar }\end{array}$ \\
\hline $\mathbf{3}$ & $\begin{array}{l}\text { Rama izquierda de la arteria } \\
\text { pulmonar }\end{array}$ \\
\hline $\mathbf{4}$ & $\begin{array}{l}\text { Rama derecha de la arteria } \\
\text { pulmonar }\end{array}$ \\
\hline $\mathbf{5}$ & Tronco bronquial ascendente \\
\hline $\mathbf{6}$ & Tronco arterial anterior \\
\hline $\mathbf{7}$ & $\begin{array}{l}\text { Tronco arterial descendente } \\
\text { o interlobar izquierdo }\end{array}$ \\
\hline $\mathbf{8}$ & Vena cava inferior \\
\hline $\mathbf{9}$ & Vena cava superior \\
\hline $\mathbf{1 0}$ & Bronquio principal izquierdo \\
\hline
\end{tabular}
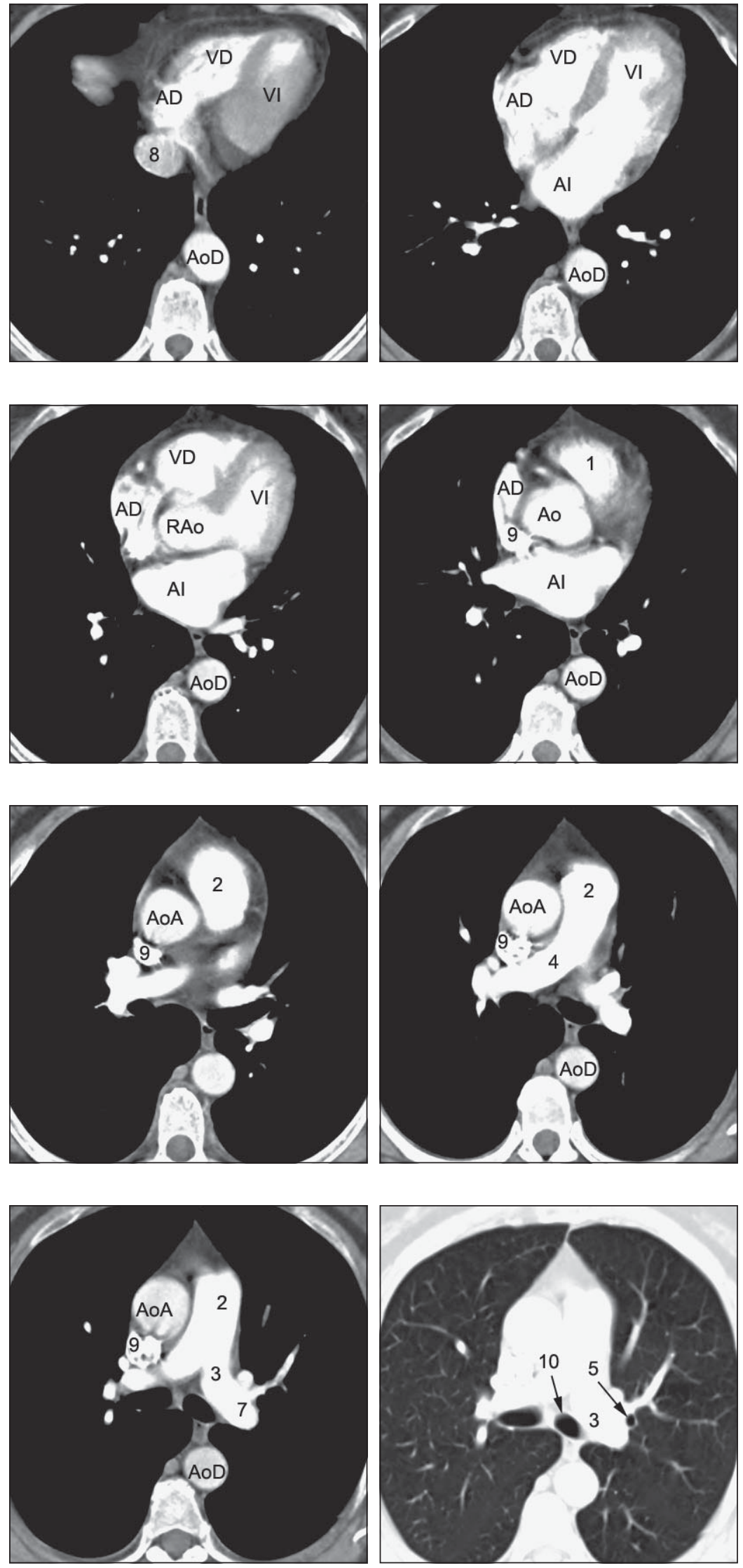


\section{Vascularización pulmonar izquierda}

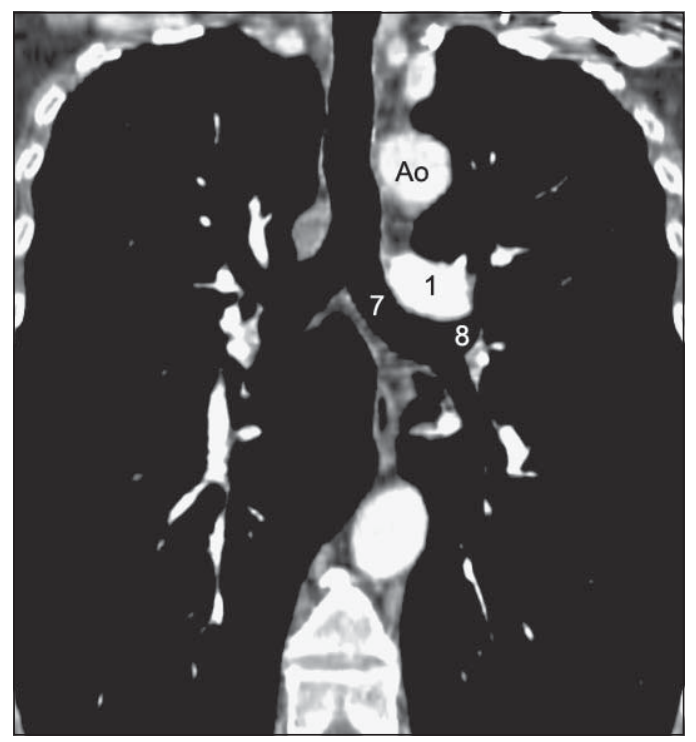

\begin{tabular}{|l|l|}
\hline Ao & Aorta \\
\hline AI & Auricula izquierda \\
\hline AD & Auricula derecha \\
\hline VD & Ventrículo derecho \\
\hline VI & Ventrículo izquierdo \\
\hline VCS & Vena cava \\
\hline $\mathbf{1}$ & Rama izquierda de la arteria pulmonar \\
\hline $\mathbf{2}$ & Rama derecha de la arteria pulmonar \\
\hline $\mathbf{3}$ & Tronco ascendente \\
\hline $\mathbf{5}$ & Tronco arterial descendente o interlobar \\
\hline $\mathbf{6}$ & Tronco arterial anterior \\
\hline $\mathbf{7}$ & Bronquio principal izquierdo \\
\hline $\mathbf{8}$ & Bronquio lobar superior izquierdo \\
\hline $\mathbf{9}$ & Bronquio lobar inferior izquierdo \\
\hline
\end{tabular}
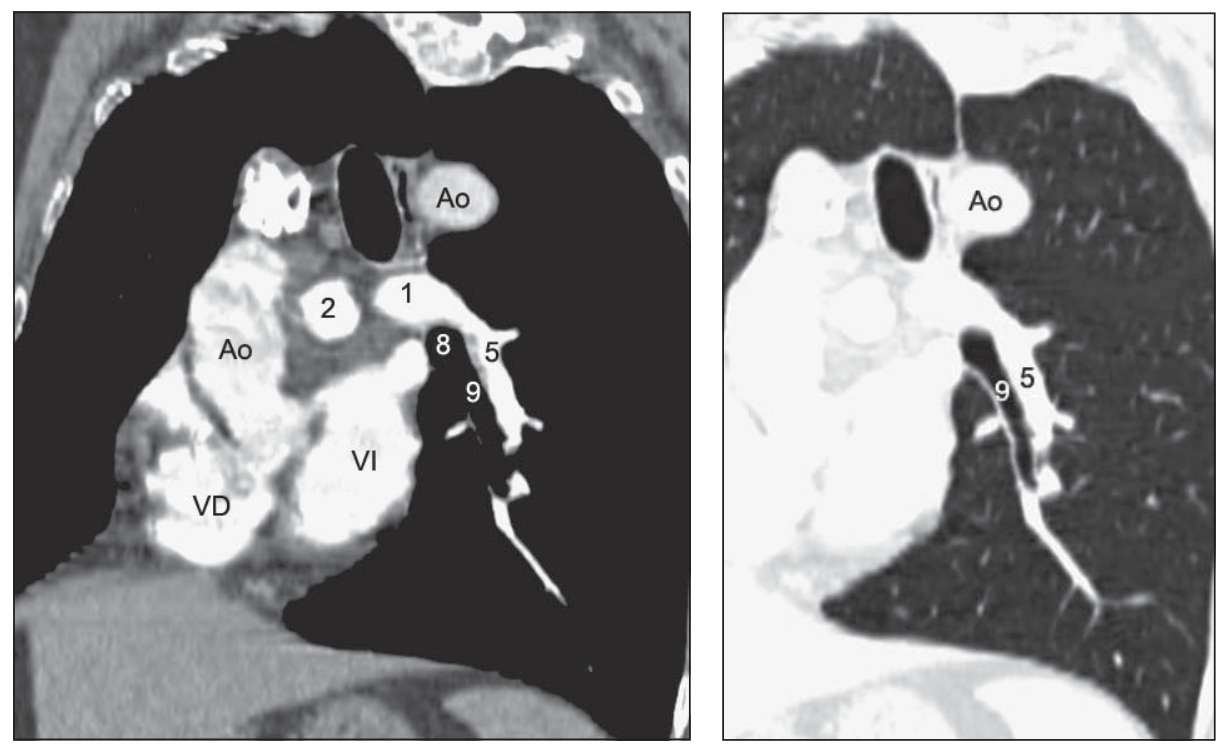

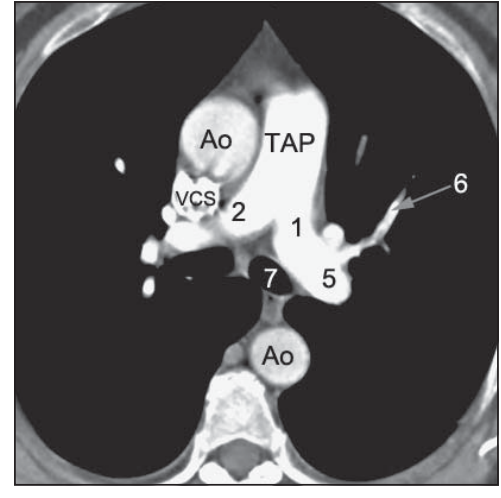

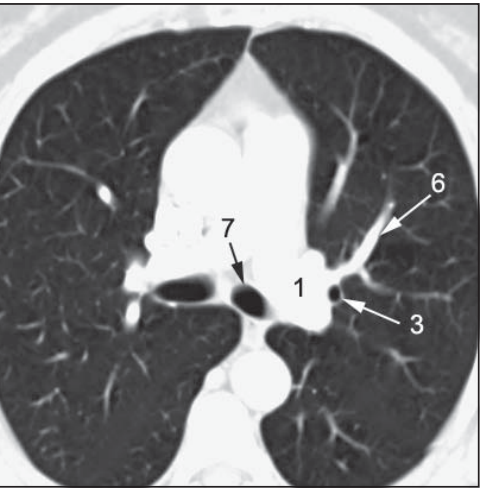

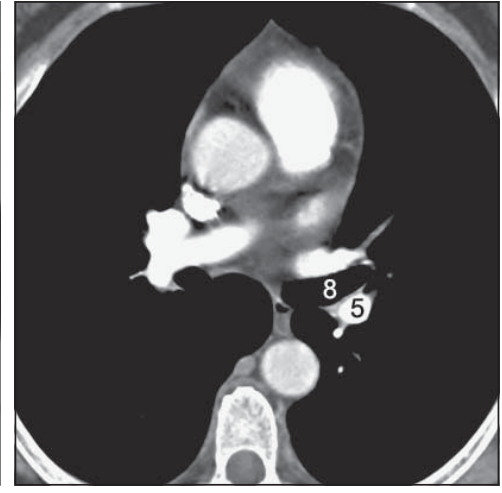

Rev Chil Enf Respir 2012; 28: 109-137 
Vascularización pulmonar derecha

\begin{tabular}{|l|l|}
\hline Ao & Aorta \\
\hline AoD & Aorta descendente \\
\hline TSVD & Tracto de salida del ventrículo derecho \\
\hline VD & Ventrículo derecho \\
\hline VI & Ventrículo izquierdo \\
\hline AI & Aurícula izquierda \\
\hline
\end{tabular}

\begin{tabular}{|l|l|}
\hline $\mathbf{1}$ & Rama derecha de la arteria pulmonar \\
\hline $\mathbf{2}$ & Tronco arterial anterior \\
\hline $\mathbf{3}$ & Tronco arterial descendente o interlobar \\
\hline $\mathbf{4}$ & Bronquio principal derecho \\
\hline $\mathbf{5}$ & Bronquio intermediario \\
\hline $\mathbf{6}$ & Bronquio lobar medio \\
\hline $\mathbf{7}$ & Bronquio lobar inferior \\
\hline $\mathbf{8}$ & Tronco venoso superior \\
\hline
\end{tabular}
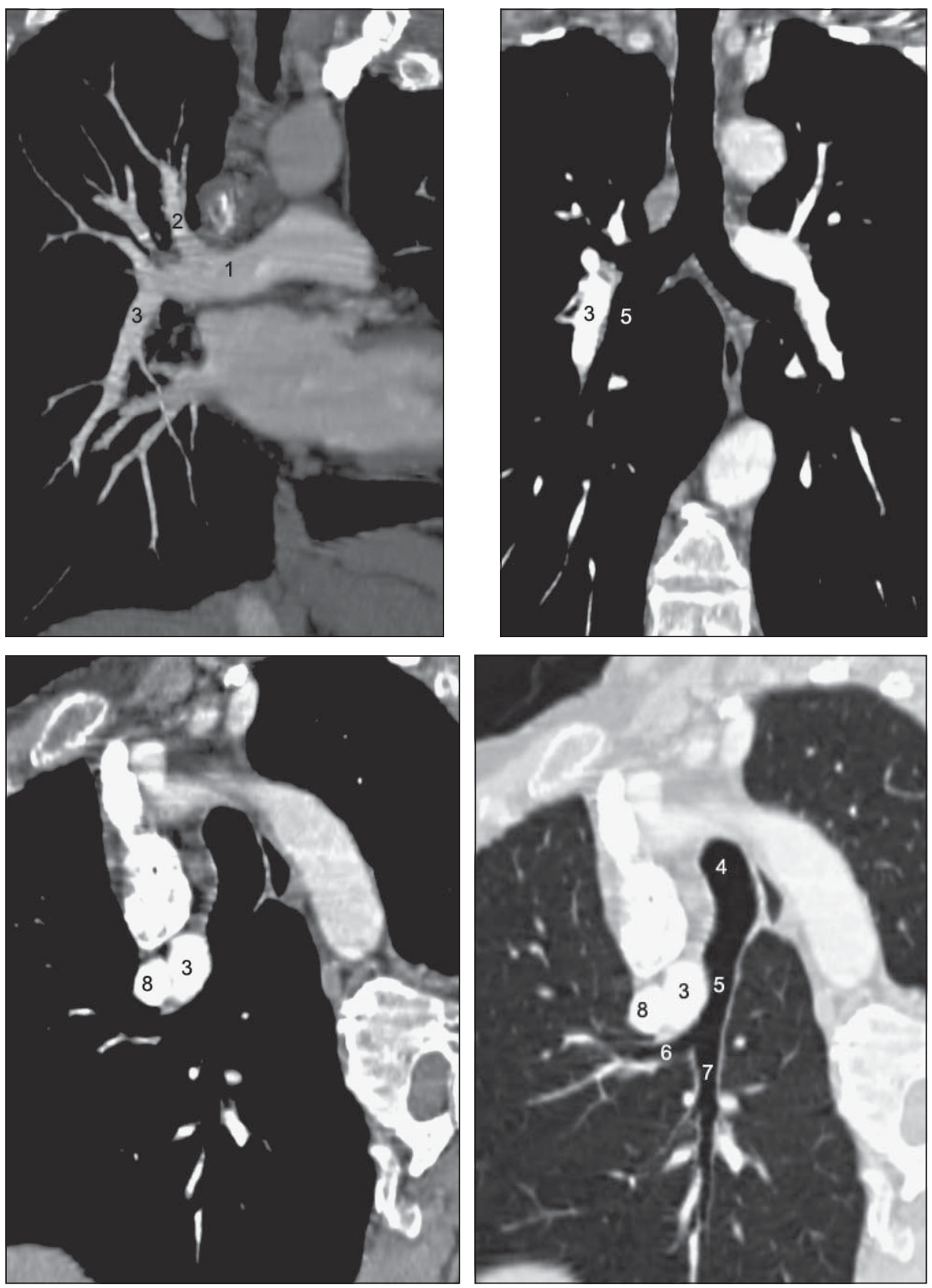


\begin{tabular}{|l|l|}
\hline Ao & Aorta \\
\hline AoD & Aorta descendente \\
\hline TSVD & Tracto de salida del ventrículo derecho \\
\hline VD & Ventrículo derecho \\
\hline VI & Ventrículo izquierdo \\
\hline AI & Aurícula izquierda \\
\hline $\mathbf{1}$ & Rama derecha de la arteria pulmonar \\
\hline $\mathbf{2}$ & Tronco arterial anterior \\
\hline $\mathbf{3}$ & Tronco arterial descendente o interlobar \\
\hline $\mathbf{4}$ & Bronquio principal derecho \\
\hline $\mathbf{5}$ & Bronquio intermediario \\
\hline $\mathbf{6}$ & Bronquio lobar medio \\
\hline $\mathbf{7}$ & Bronquio lobar inferior \\
\hline $\mathbf{8}$ & Tronco venoso superior \\
\hline
\end{tabular}
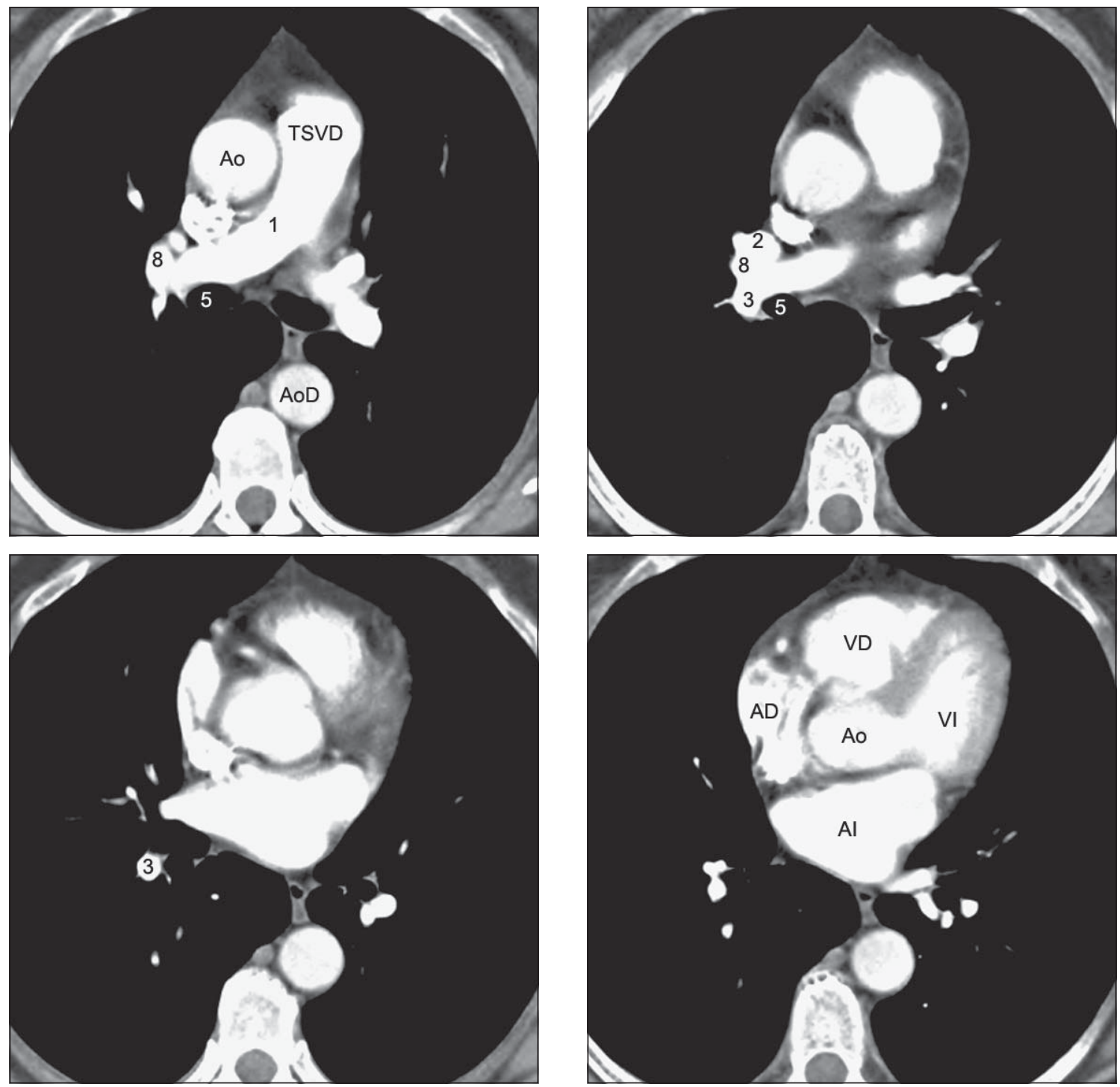


\section{Sistema venoso pulmonar}

\begin{tabular}{|l|l|}
\hline AI & Aurícula izquierda \\
\hline Ao & Aorta \\
\hline VCS & Vena cava superior \\
\hline $\mathbf{1}$ & Tronco venoso superior \\
\hline $\mathbf{2}$ & Tronco venoso basal \\
\hline $\mathbf{3}$ & Rama izquierda de la arteria pulmonar \\
\hline $\mathbf{4}$ & Rama derecha de la arteria pulmonar \\
\hline $\mathbf{5}$ & Arteria descendente o interlobar \\
\hline $\mathbf{6}$ & Tronco arterial anterior \\
\hline $\mathbf{7}$ & Bronquio intermediario \\
\hline $\mathbf{8}$ & Bronquio lobar medio \\
\hline $\mathbf{9}$ & Bronquio lobar inferior \\
\hline
\end{tabular}
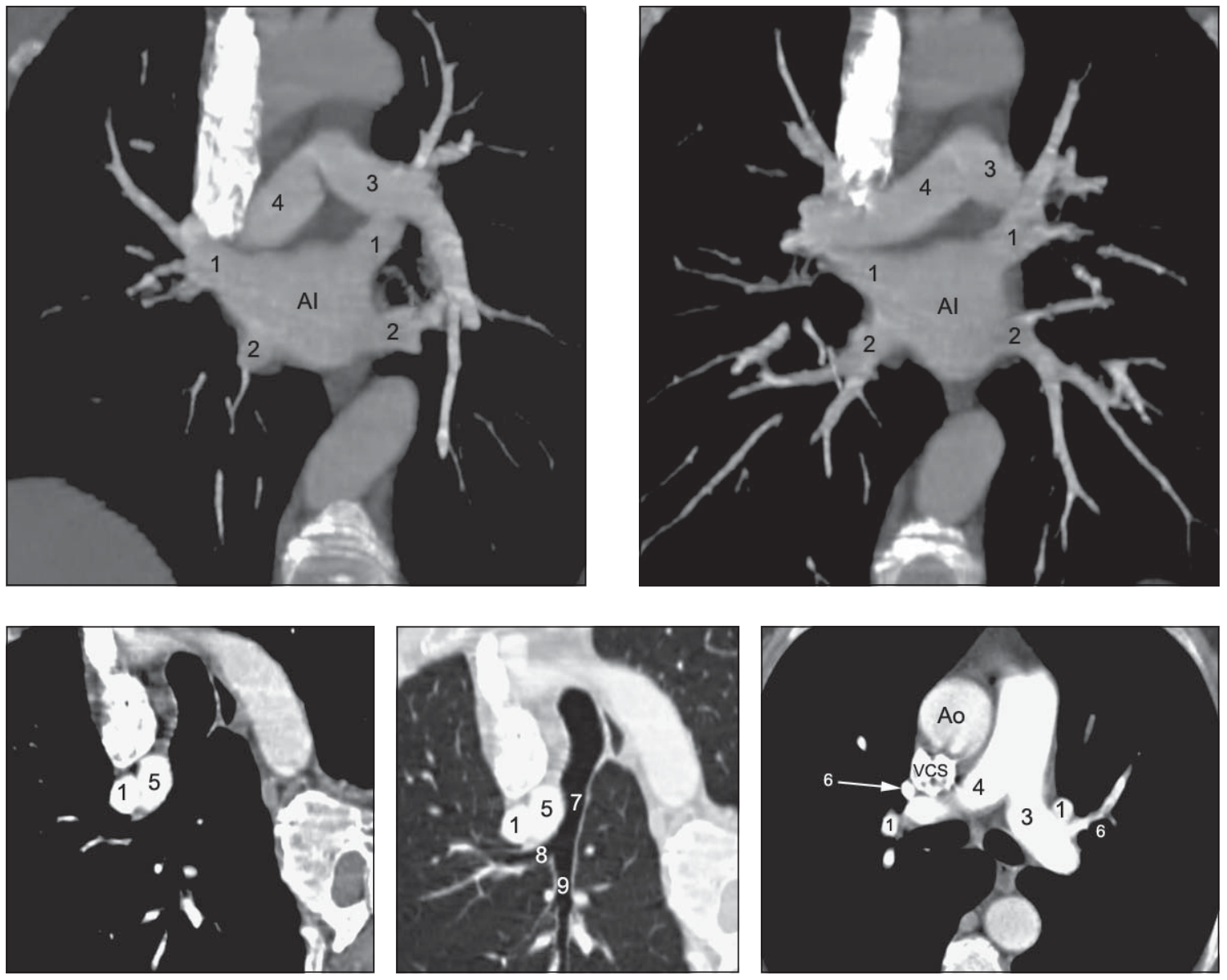


\section{Hilios}

\section{Hilio derecho}

\begin{tabular}{|r|l|}
\hline $\mathbf{1}$ & Tronco arterial anterior \\
\hline $\mathbf{2}$ & Arteria interlobar \\
\hline $\mathbf{3}$ & Tronco venoso superior \\
\hline $\mathbf{4}$ & Bronquio principal derecho \\
\hline $\mathbf{5}$ & Bronquio lobar superior \\
\hline $\mathbf{5 a}$ & Bronquio segmentario anterior \\
\hline $\mathbf{5 b}$ & Bronquio segmentario posterior \\
\hline $\mathbf{5 c}$ & Bronquio segmentario apical \\
\hline $\mathbf{6}$ & Bronquio intermediario \\
\hline $\mathbf{7}$ & Bronquio lobar medio \\
\hline $\mathbf{8}$ & Bronquio segmentario medial \\
\hline $\mathbf{9}$ & Bronquio segmentario lateral \\
\hline $\mathbf{1 0}$ & Bronquio lobar inferior \\
\hline $\mathbf{1 1}$ & Bronquio segmentario apical del lóbulo inferior \\
\hline
\end{tabular}
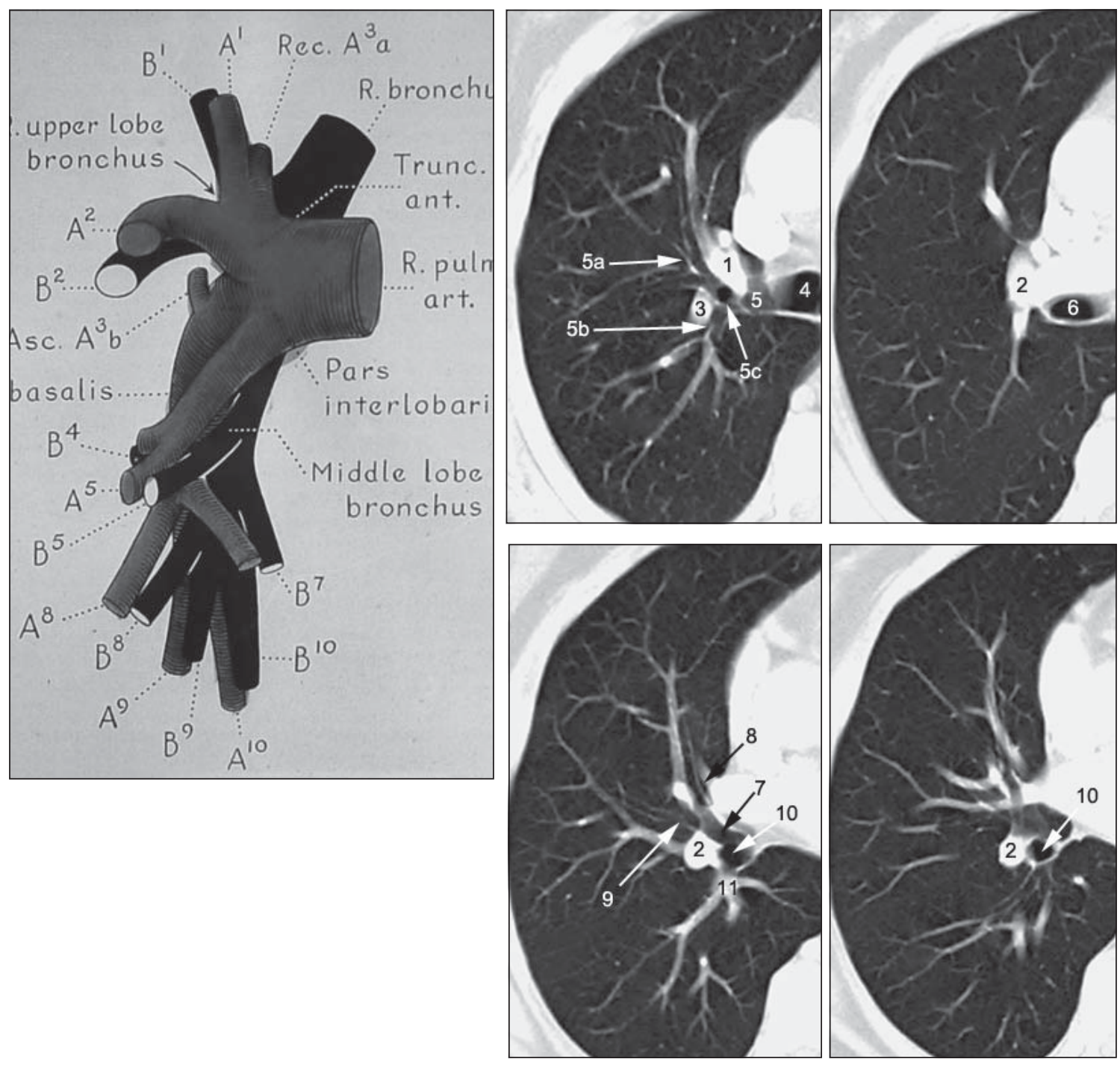


\section{Hilio izquierdo}

\begin{tabular}{|l|l|}
\hline $\mathbf{1}$ & Rama izquierda de la arteria pulmonar \\
\hline $\mathbf{2}$ & Arteria interlobar \\
\hline $\mathbf{3}$ & Bronquio principal izquierdo \\
\hline $\mathbf{4}$ & Bronquio lobar superior \\
\hline $\mathbf{5}$ & Tronco bronquial ascendente \\
\hline $\mathbf{6}$ & Bronquio lingular superior \\
\hline $\mathbf{7}$ & Bronquio lobar inferior \\
\hline $\mathbf{8}$ & Bronquio segmentario apical del lóbulo inferior \\
\hline
\end{tabular}
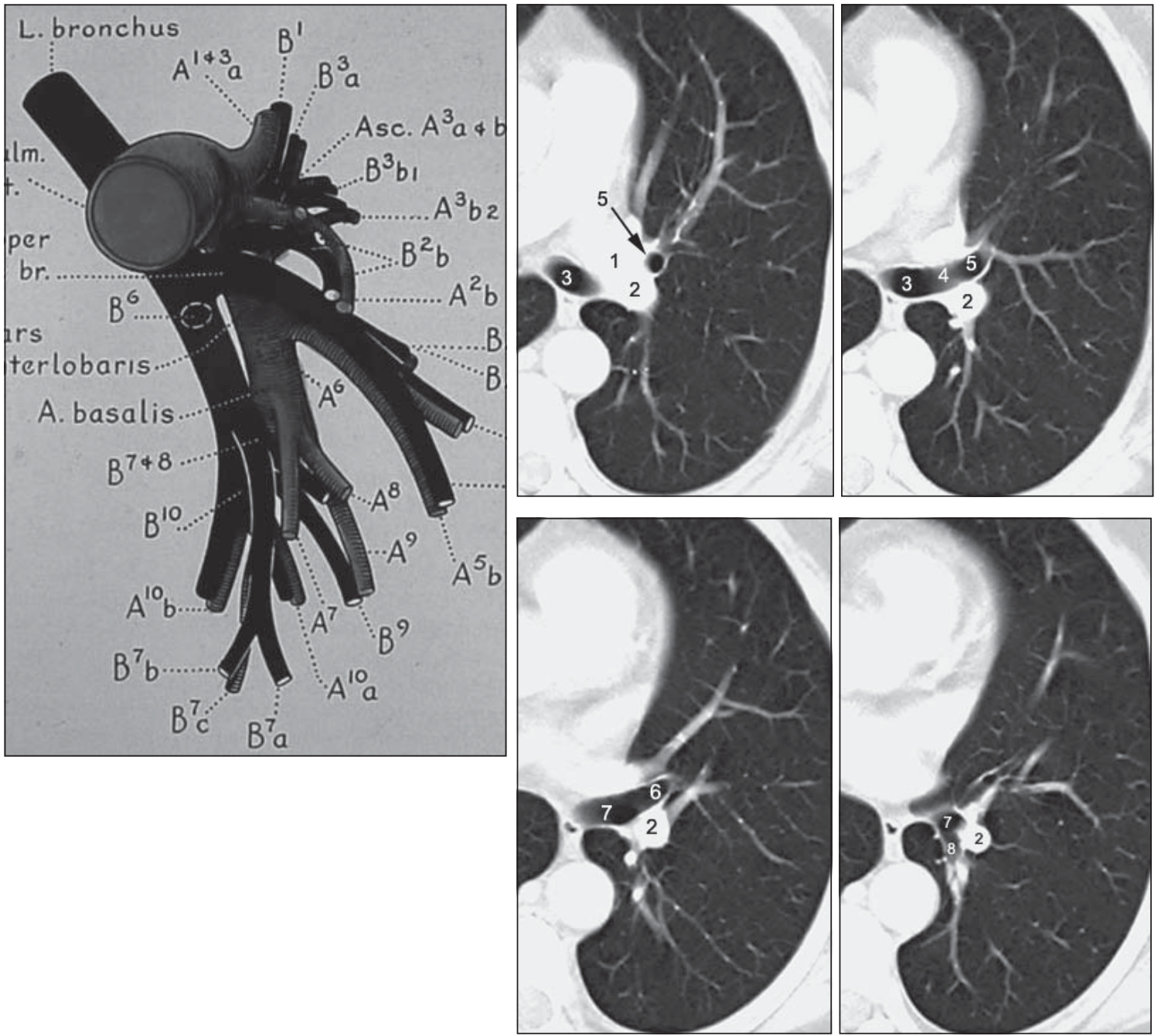


\section{Anatomía mediastínica}

\begin{tabular}{|l|l|}
\hline RCM & Región cervico-mediastínica \\
\hline MA & Mediastino anterior \\
\hline MM & Mediastino medio \\
\hline MP & Mediastino posterior \\
\hline RPE & Región paraespinal \\
\hline
\end{tabular}
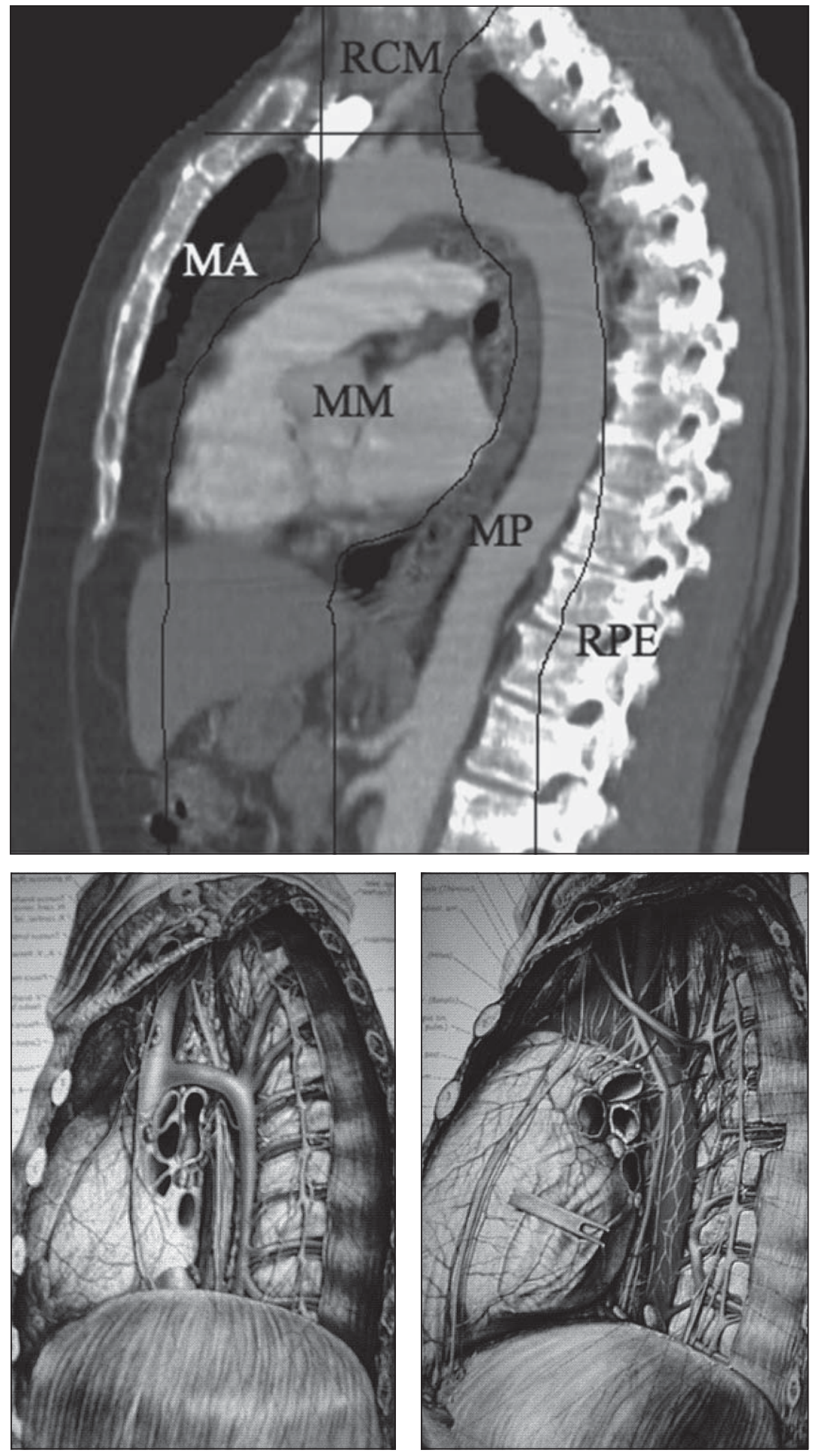


\begin{tabular}{|l|l|}
\hline VI & Ventrículo izquierdo \\
\hline AD & Auricula derecha \\
\hline Ao & Aorta \\
\hline MA & Mediastino anterior \\
\hline
\end{tabular}

\begin{tabular}{|l|l|}
\hline $\mathbf{1}$ & Angulo cardio-frénico \\
\hline $\mathbf{2}$ & Vena cava superior \\
\hline $\mathbf{3}$ & Tronco de la arteria pulmonar \\
\hline $\mathbf{4}$ & Arteria braquiocefálica \\
\hline $\mathbf{5}$ & Carótida izquierda \\
\hline $\mathbf{6}$ & Arteria subclavia izquierda \\
\hline
\end{tabular}

\section{Mediastino anterior}
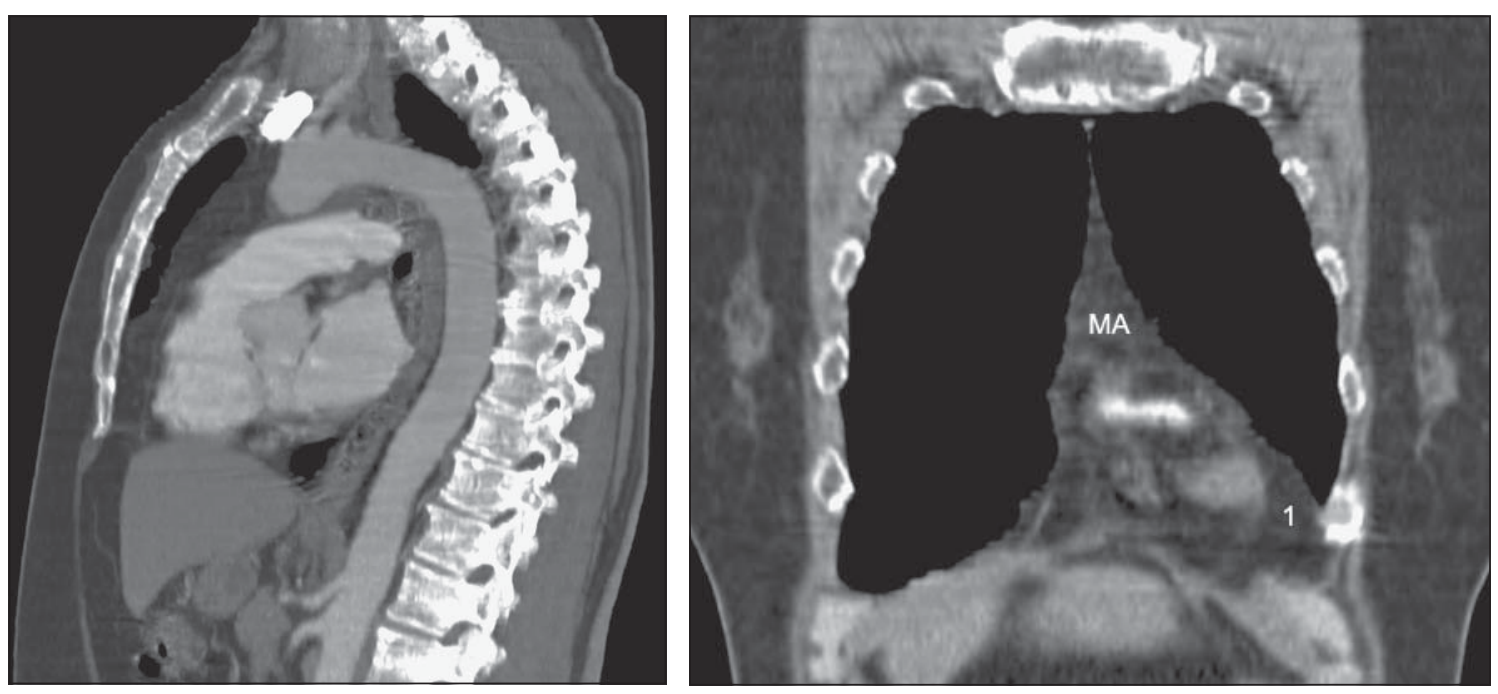

\section{Mediastino medio}
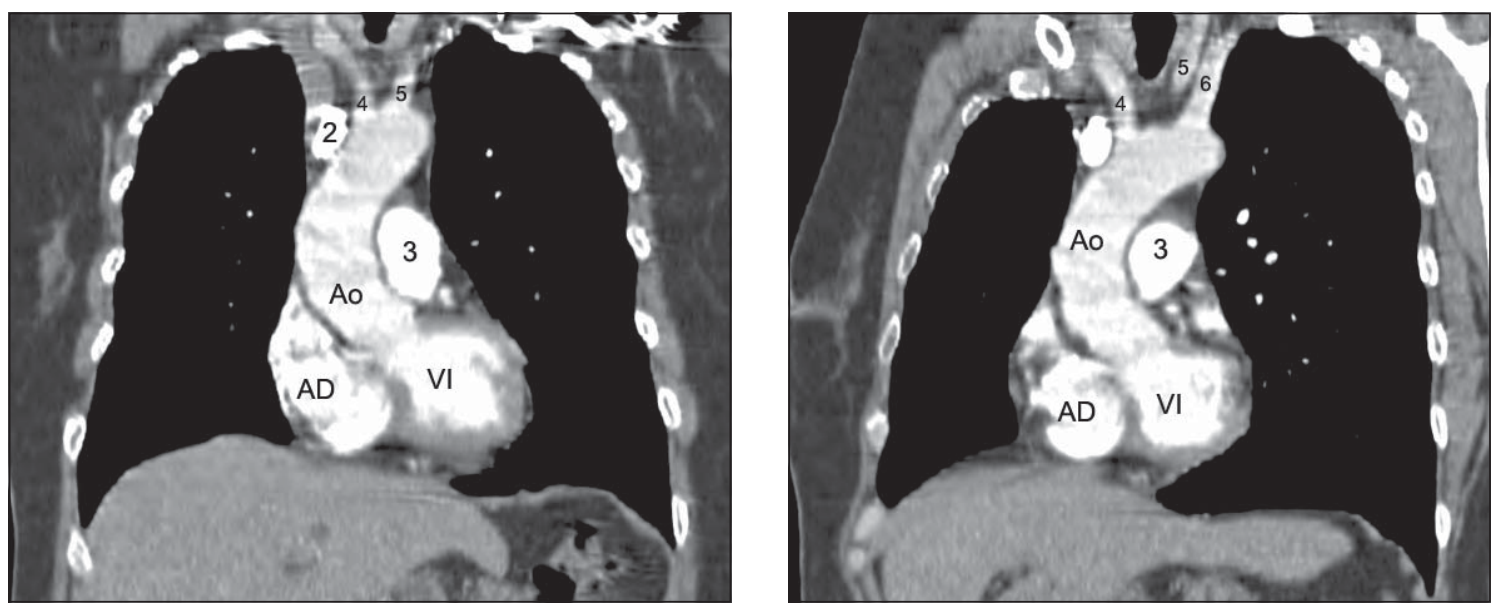


\begin{tabular}{|l|l|}
\hline AI & Aurícula izquierda \\
\hline Ao & Aorta \\
\hline RAo & Raíz aórtica \\
\hline $\mathbf{1}$ & Espacio pretraqueal \\
\hline $\mathbf{2}$ & Vena cava superior \\
\hline $\mathbf{3}$ & Tracto de salida del ventrículo derecho \\
\hline
\end{tabular}

\begin{tabular}{|l|l|}
\hline $\mathbf{4}$ & Tronco de la arteria pulmonar \\
\hline $\mathbf{5}$ & Rama derecha de la arteria pulmonar \\
\hline $\mathbf{6}$ & Rama izquierda de la arteria pulmonar \\
\hline $\mathbf{7}$ & Vena ázigos \\
\hline $\mathbf{8}$ & Espacio subaórtico \\
\hline $\mathbf{9}$ & Espacio subcarinal \\
\hline
\end{tabular}

\section{Mediastino medio}
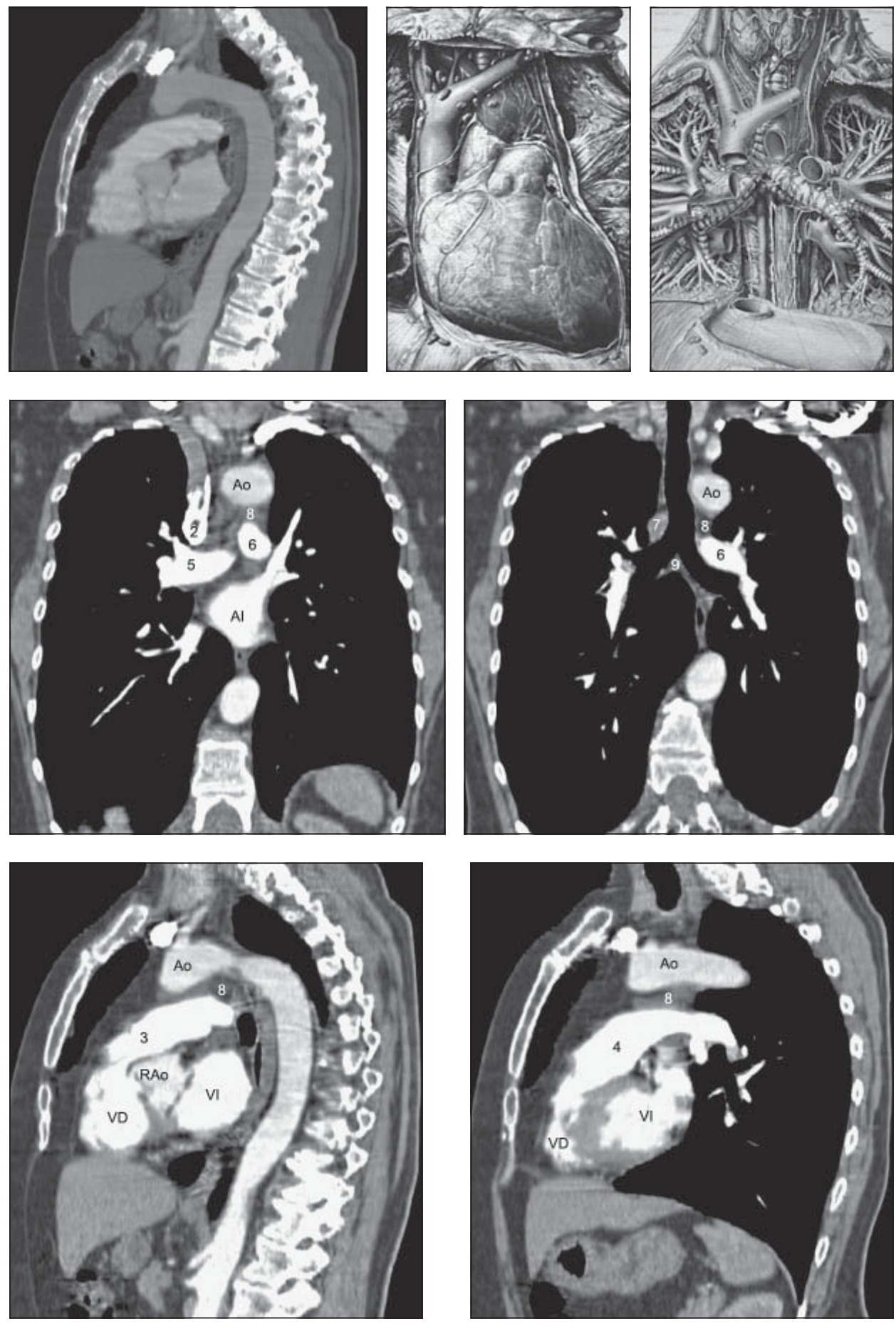


\begin{tabular}{|l|l|}
\hline $\mathbf{1}$ & Vena ázigos \\
\hline $\mathbf{2}$ & Cayado de la vena ázigos \\
\hline $\mathbf{3}$ & Esófago \\
\hline
\end{tabular}

\section{Mediastino posterior}
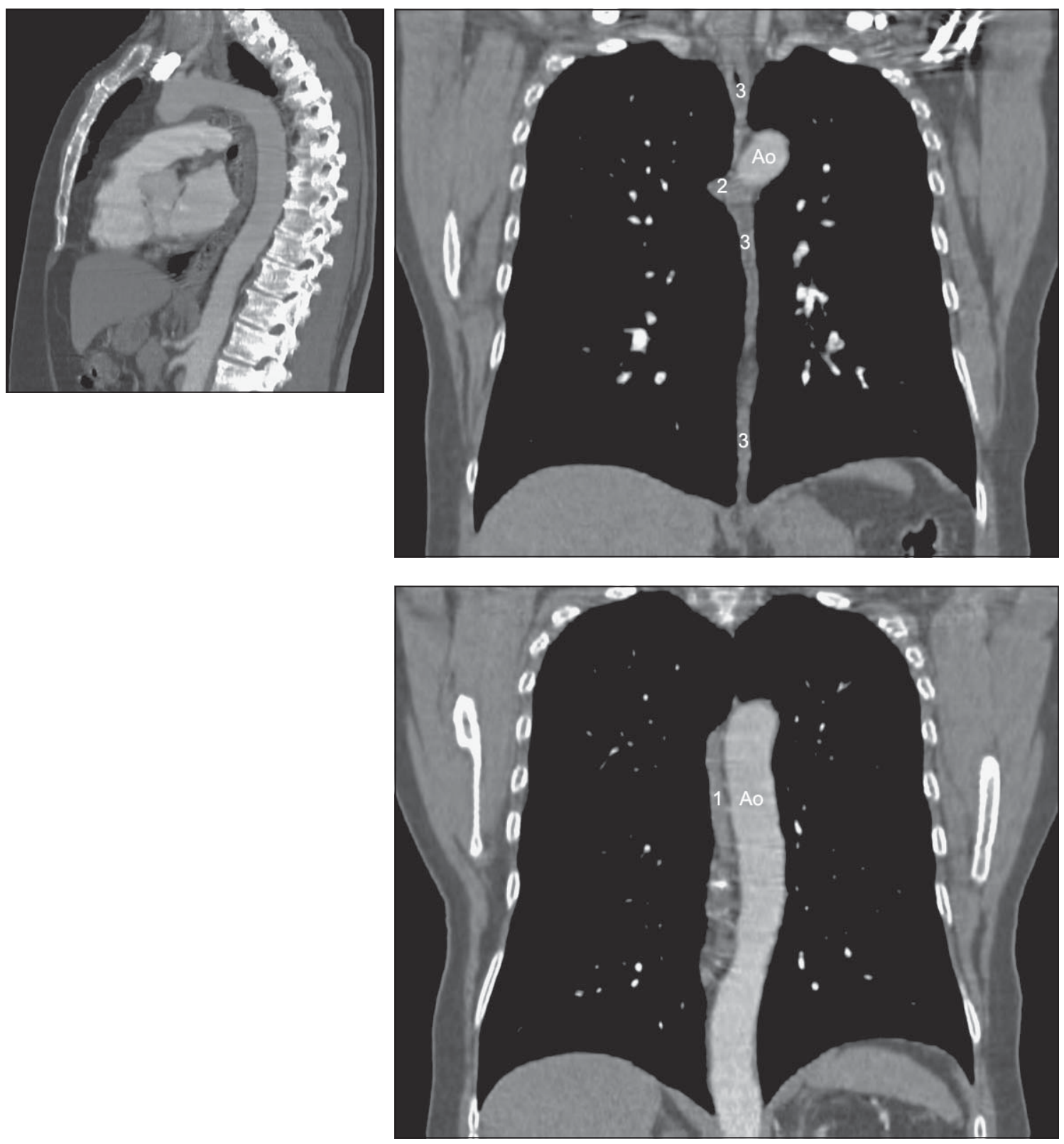


\section{Recesos paraespinales}

\begin{tabular}{|l|l|}
\hline $\mathbf{1}$ & Recesos paraespinales \\
\hline $\mathbf{2}$ & Canal raquimedular \\
\hline $\mathbf{3}$ & Agujero de conjunción \\
\hline
\end{tabular}
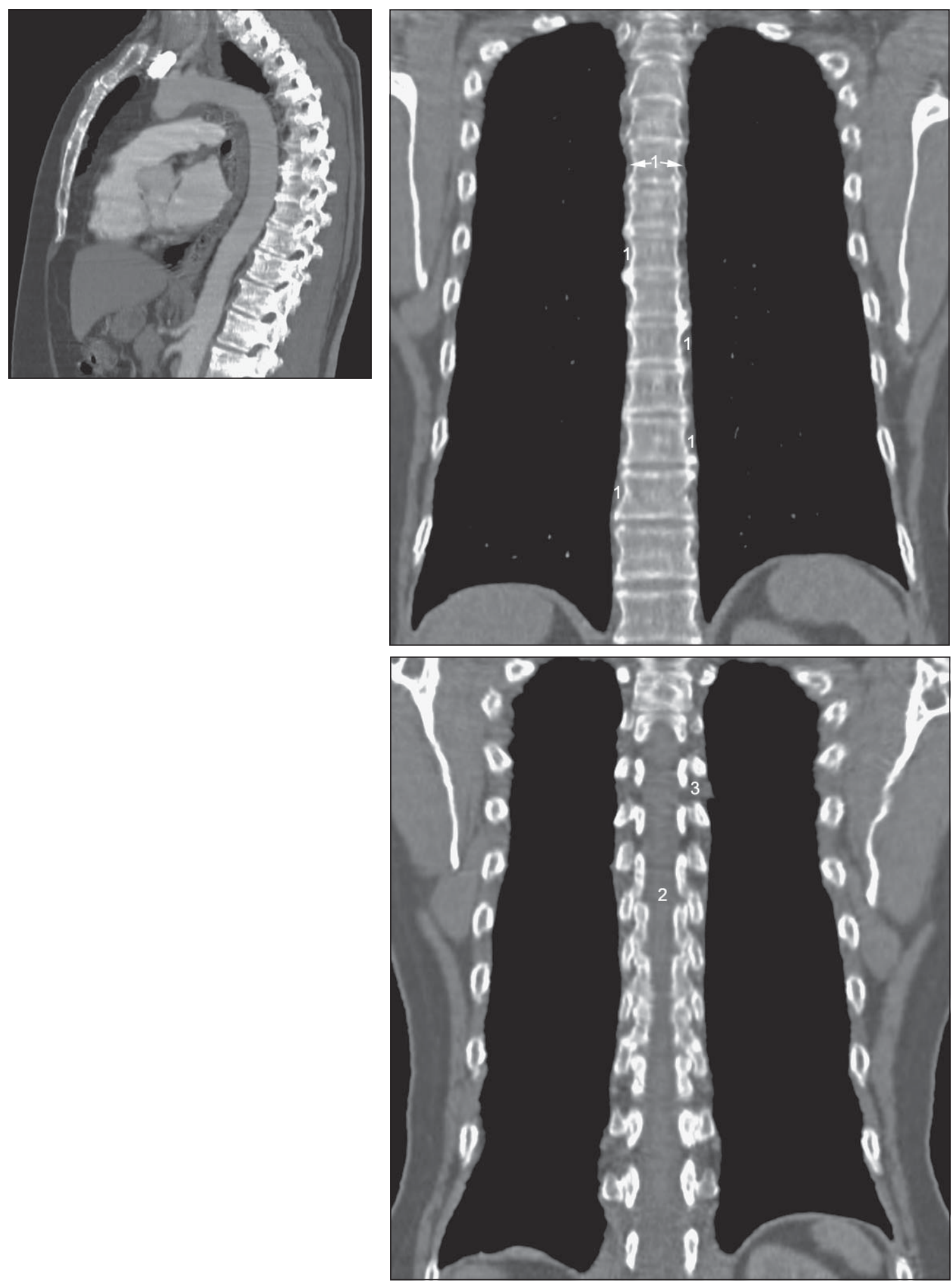


\begin{tabular}{|c|l|}
\hline RAo & Raíz aórtica \\
\hline MA & Mediastino anterior \\
\hline MM & Mediastino medio \\
\hline MP & Mediastino posterior \\
\hline Ao & Aorta \\
\hline $\mathbf{1}$ & Espacio supraclavicular \\
\hline $\mathbf{2}$ & Espacio subgótico \\
\hline $\mathbf{3}$ & Tiroides \\
\hline $\mathbf{4}$ & Carótidas \\
\hline $\mathbf{5}$ & Tronco braquiocefálico \\
\hline $\mathbf{6}$ & Arteria sublavia izquierda \\
\hline $\mathbf{7}$ & Vena yugular \\
\hline $\mathbf{8}$ & Vena sublavia izquierda \\
\hline $\mathbf{9}$ & Tronco venoso braquiocefálico derecho \\
\hline $\mathbf{1 0}$ & Tronco venoso braquiocefálico izquierdo \\
\hline
\end{tabular}

\begin{tabular}{|l|l|}
\hline $\mathbf{1 1}$ & Confluencia de venas braquiocefálicas \\
\hline $\mathbf{1 2}$ & Vena cava superior \\
\hline $\mathbf{1 3}$ & Cayado de la vena ázigos \\
\hline $\mathbf{1 4}$ & Vena ázigos \\
\hline $\mathbf{1 5}$ & Espacio pretraqueal \\
\hline $\mathbf{1 6}$ & Espacio paratraqueal \\
\hline $\mathbf{1 7}$ & Espacio subaórtico \\
\hline $\mathbf{1 8}$ & Espacio subcarinal \\
\hline $\mathbf{1 9}$ & Tronco de la arteria pulmonar \\
\hline $\mathbf{2 0}$ & Arteria interlobar \\
\hline $\mathbf{2 1}$ & Tronco venoso superior \\
\hline $\mathbf{2 2}$ & Ángulo cardiofrénico \\
\hline $\mathbf{2 3}$ & Vena cava inferior \\
\hline $\mathbf{2 4}$ & Esófago \\
\hline $\mathbf{2 5}$ & Espacio precarinal \\
\hline
\end{tabular}
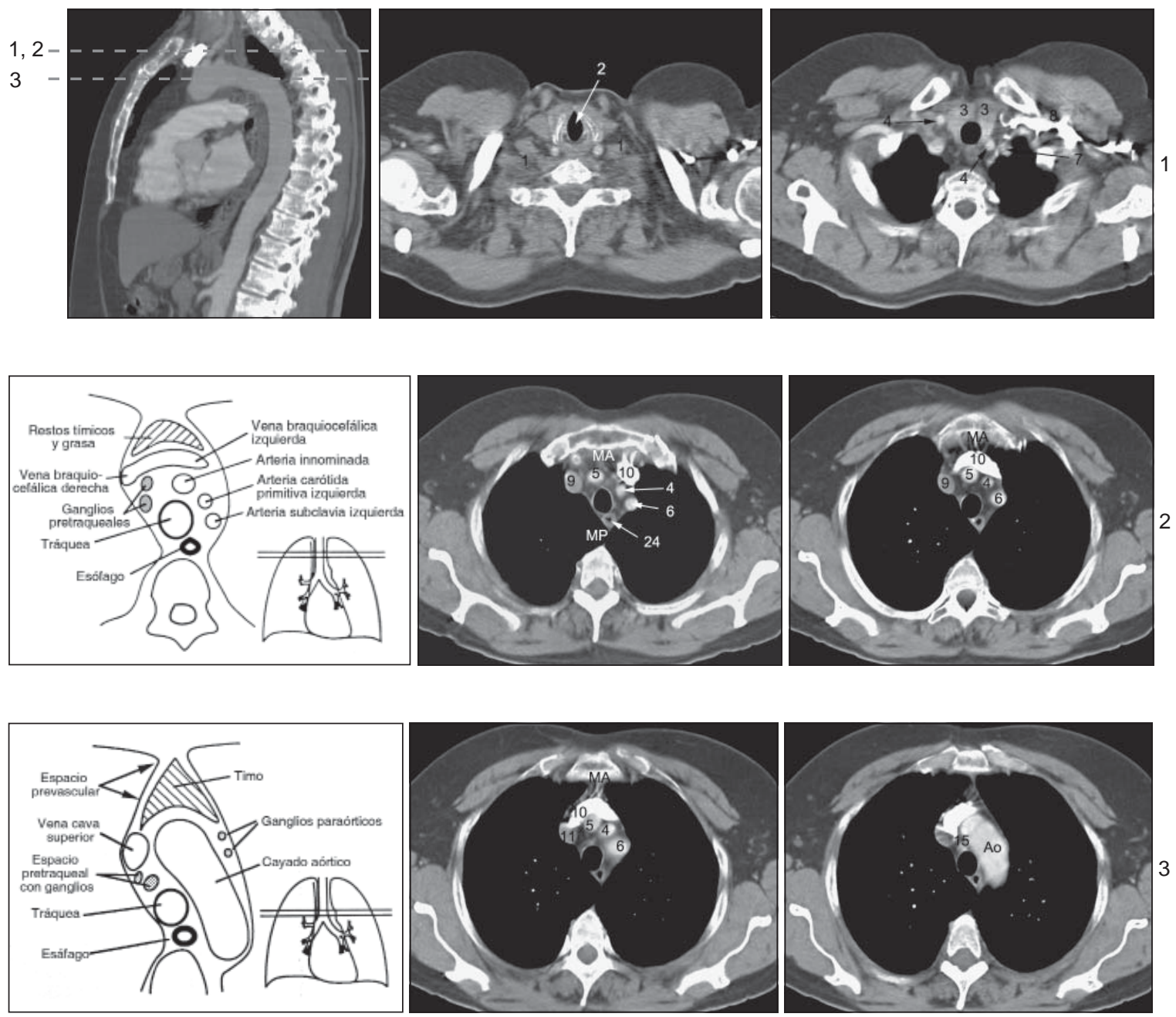


\begin{tabular}{|c|l|}
\hline RAo & Raíz aórtica \\
\hline MA & Mediastino anterior \\
\hline MM & Mediastino medio \\
\hline MP & Mediastino posterior \\
\hline Ao & Aorta \\
\hline $\mathbf{1}$ & Espacio supraclavicular \\
\hline $\mathbf{2}$ & Espacio subgótico \\
\hline $\mathbf{3}$ & Tiroides \\
\hline $\mathbf{4}$ & Carótidas \\
\hline $\mathbf{5}$ & Tronco braquiocefálico \\
\hline $\mathbf{6}$ & Arteria sublavia izquierda \\
\hline $\mathbf{7}$ & Vena yugular \\
\hline $\mathbf{8}$ & Vena sublavia izquierda \\
\hline $\mathbf{9}$ & $\begin{array}{l}\text { Tronco venoso braquiocefálico } \\
\text { derecho }\end{array}$ \\
\hline $\mathbf{1 0}$ & $\begin{array}{l}\text { Tronco venoso braquiocefálico } \\
\text { izquierdo }\end{array}$ \\
\hline
\end{tabular}

\begin{tabular}{|l|l|}
\hline $\mathbf{1 1}$ & $\begin{array}{l}\text { Confluencia de venas } \\
\text { braquiocefálicas }\end{array}$ \\
\hline $\mathbf{1 2}$ & Vena cava superior \\
\hline $\mathbf{1 3}$ & Cayado de la vena ázigos \\
\hline $\mathbf{1 4}$ & Vena ázigos \\
\hline $\mathbf{1 5}$ & Espacio pretraqueal \\
\hline $\mathbf{1 6}$ & Espacio paratraqueal \\
\hline $\mathbf{1 7}$ & Espacio subaórtico \\
\hline $\mathbf{1 8}$ & Espacio subcarinal \\
\hline $\mathbf{1 9}$ & Tronco de la arteria pulmonar \\
\hline $\mathbf{2 0}$ & Arteria interlobar \\
\hline $\mathbf{2 1}$ & Tronco venoso superior \\
\hline $\mathbf{2 2}$ & Ángulo cardiofrénico \\
\hline $\mathbf{2 3}$ & Vena cava inferior \\
\hline $\mathbf{2 4}$ & Esófago \\
\hline $\mathbf{2 5}$ & Espacio precarinal \\
\hline & \multicolumn{2}{|l}{} \\
\hline
\end{tabular}
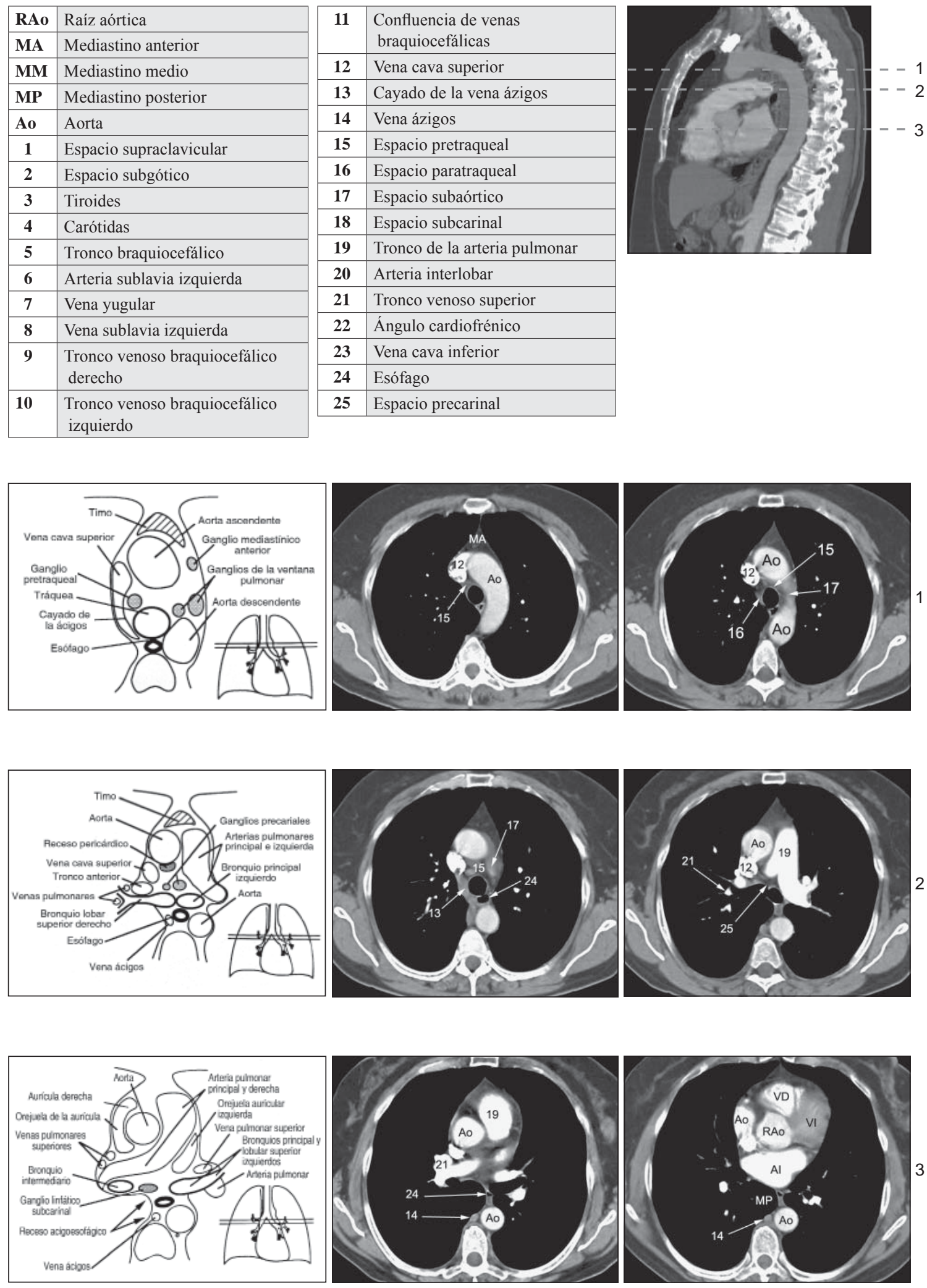


\begin{tabular}{|c|l|}
\hline RAo & Raíz aórtica \\
\hline MA & Mediastino anterior \\
\hline MM & Mediastino medio \\
\hline MP & Mediastino posterior \\
\hline Ao & Aorta \\
\hline $\mathbf{1}$ & Espacio supraclavicular \\
\hline $\mathbf{2}$ & Espacio subgótico \\
\hline $\mathbf{3}$ & Tiroides \\
\hline $\mathbf{4}$ & Carótidas \\
\hline $\mathbf{5}$ & Tronco braquiocefálico \\
\hline $\mathbf{6}$ & Arteria sublavia izquierda \\
\hline $\mathbf{7}$ & Vena yugular \\
\hline $\mathbf{8}$ & Vena sublavia izquierda \\
\hline $\mathbf{9}$ & Tronco venoso braquiocefálico derecho \\
\hline $\mathbf{1 0}$ & Tronco venoso braquiocefálico izquierdo \\
\hline
\end{tabular}

\begin{tabular}{|l|l|}
\hline $\mathbf{1 1}$ & Confluencia de venas braquiocefálicas \\
\hline $\mathbf{1 2}$ & Vena cava superior \\
\hline $\mathbf{1 3}$ & Cayado de la vena ázigos \\
\hline $\mathbf{1 4}$ & Vena ázigos \\
\hline $\mathbf{1 5}$ & Espacio pretraqueal \\
\hline $\mathbf{1 6}$ & Espacio paratraqueal \\
\hline $\mathbf{1 7}$ & Espacio subaórtico \\
\hline $\mathbf{1 8}$ & Espacio subcarinal \\
\hline $\mathbf{1 9}$ & Tronco de la arteria pulmonar \\
\hline $\mathbf{2 0}$ & Arteria interlobar \\
\hline $\mathbf{2 1}$ & Tronco venoso superior \\
\hline $\mathbf{2 2}$ & Ángulo cardiofrénico \\
\hline $\mathbf{2 3}$ & Vena cava inferior \\
\hline $\mathbf{2 4}$ & Esófago \\
\hline $\mathbf{2 5}$ & Espacio precarinal \\
\hline
\end{tabular}
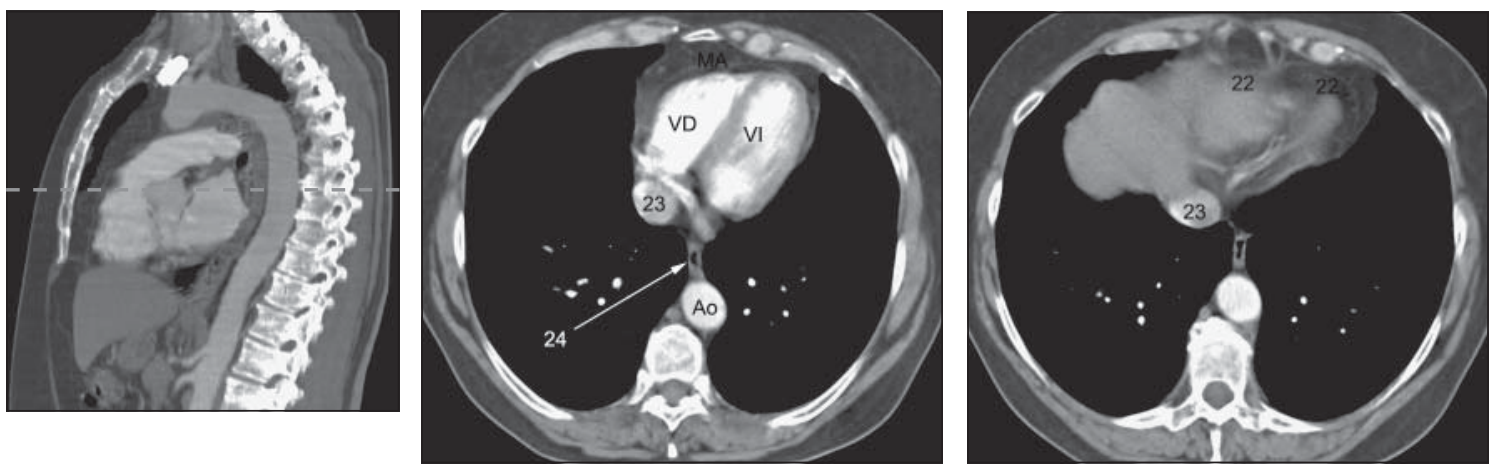

\section{Referencias bibliográficas}

1.- SABBAGH E. Imagenología. En: Enfermedades Respiratorias. Eds. Rodríguez JC, Undurraga A. 2a edición. Editorial Mediterráneo Ltda. Santiago. 2011, págs 129158.

2.- MÜLLER N L, FRASER R S, COLMAN N C, PARE P D. Radiologic diagnosis of diseases of the chest. Phi- ladelphia, W. B. Saunders Co. 2001.

3.- KIEFFER S A, HEITZMAN E R. An atlas of crosssectional anatomy. Computed tomography, ultrasound, radiography gross anatomy. New York, Harper and Row Publishers Inc, 1979.

4.- WEBB W R, MÜLLER N L, NAIDICHI D P. High resolution CT of the lung. Philadelphia: Lippincott-raven, 2001.

Correspondencia a:

Dr. Eduardo Sabbagh P.

Servicio de Radiología, Instituto Nacional del Tórax.

J. M. Infante 717. Providencia. Santiago, Chile.

E-mail: edo.sabbagh@vtr.net 